RODRIGO MARTINS RIBEIRO

Inclusão de Gordura na Alimentação de Eqüinos 
RODRIGO MARTINS RIBEIRO

\title{
Inclusão de Gordura na Alimentação de Eqüinos
}

\author{
Dissertação apresentada ao \\ Programa de Pós-Graduação em \\ Nutrição e Produção Animal da \\ Faculdade de Medicina Veterinária e \\ Zootecnia da Universidade de São \\ Paulo para obtenção do Título de \\ Mestre em Medicina Veterinária
}

\section{Departamento:}

Nutrição e Produção Animal

Área de concentração:

Nutrição e Produção Animal

\section{Orientador:}

Prof. Dr. Alexandre Augusto de

Oliveira Gobesso 
Autorizo a reprodução parcial ou total desta obra, para fins acadêmicos, desde que citada a fonte.

DADOS INTERNACIONAIS DE CATALOGAÇÃO-NA-PUBLICAÇÃO

(Biblioteca Virginie Buff D’Ápice da Faculdade de Medicina Veterinária e Zootecnia da Universidade de São Paulo)

Ribeiro, Rodrigo Martins

Inclusão de gordura na alimentação de eqüinos / Rodrigo Martins Ribeiro. -- Pirassununga: R. M. Ribeiro, 2007.

$68 \mathrm{f}$ : : il.

Dissertação (mestrado) - Universidade de São Paulo. Faculdade de Medicina Veterinária e Zootecnia. Departamento de Nutrição e Produção Animal, 2007.

Programa de Pós-Graduação: Nutrição e Produção Animal.

Área de concentração: Nutrição e Produção Animal.

Orientador: Prof. Dr. Alexandre Augusto de Oliveira Gobesso.

1. Aceitabilidade. 2. Colesterol. 3. Digestibilidade. 4. Eqüinos. 5. Lipídios. 6. Triglicérides. I. Título. 


\section{UNIVERSIDADE DE SÃO PAULO \\ Faculdade de Medicina Veterinária e Zootecnia}

\section{Comissão Bioética}

\section{CERTIFICADO}

Certificamos que o Projeto intitulado "Inclusão de gordura na alimentação de eqüinos", Protocolo n459a/2004, utilizando 04 (quatro) cavalos, sob a responsabilidade do Prof. Dr. Alexandre Augusto de Oliveira Gobesso, está de acordo com os princípios éticos de experimentação animal da Comissão de Bioética da Faculdade de Medicina Veterinária e Zootecnia da Universidade de São Paulo e foi aprovado "ad referendum".

(We certify that the Research "Inclusion of fat in equine diet" protocol number 459a/2004, utilizing 04 horses, under the responsibility of Prof. Dr. Alexandre Augusto de Oliveira Gobesso, agree with Ethical Principles in Animal Research adopted by Bioethic Commission of the School of Veterinary Medicine and Animal Science of University of São Paulo and was approved "ad referendun", meeting.

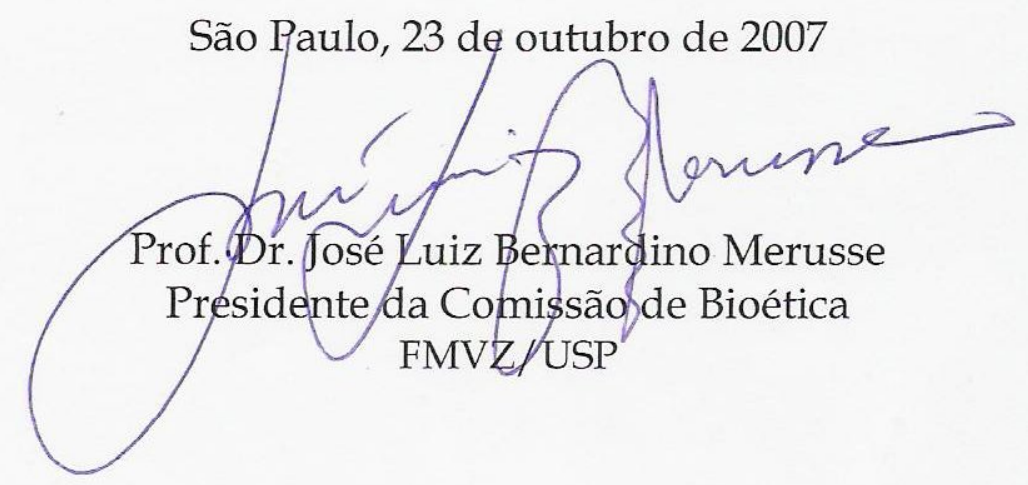

Av. Prof. Dr. Orlando Marques de Paiva, no 87 - 05508-270 - Cidade Universitária “Armando de Salles Oliveira". Fax: (11) 3032-2224 - fones: (11) 3091-7676/7671 - email: fmvz@edu.usp.br 


\section{FOLHA DE AVALIAÇÃO}

Nome: Rodrigo Martins Ribeiro

Título: Inclusão de Gordura na Alimentação de Eqüinos

Dissertação apresentada ao

Programa de Pós-Graduação em

Nutrição e Produção Animal da

Faculdade de Medicina Veterinária e

Zootecnia da Universidade de São

Paulo para obtenção do Título de

Mestre em Medicina Veterinária

Data:

Banca Examinadora:

Prof. Dr.

Instituição:

Assinatura:

Julgamento:

Prof. Dr.

Instituição:

Assinatura:

Julgamento:

Prof. Dr.

Instituição:

Assinatura:

Julgamento: 
Aos meus Pais

Altair Alves Ribeiro e

Nadir de Melo Martins Ribeiro

DEDICO 


\section{AGRADECIMENTOS}

A Deus, por estar comigo em todos os momentos da minha vida.

A minha família, por me apoiar e incentivar.

A Débora, minha namorada, pelo companheirismo, paciência e dedicação.

Ao Prof. Dr. Alexandre A. O. Gobesso, pela orientação, amizade e conhecimento transmitido.

À FAPESP pelo financiamento do experimento.

Ao Departamento de Nutrição e Produção Animal, da Faculdade de Medicina Veterinária e Zootecnia da Universidade de São Paulo, por me aceitar no curso de mestrado.

Aos funcionários e amigos do Setor de Eqüideocultura, Valdir, Maico, Beto e Sr. Jorge, pela grande ajuda e amizade.

A "família" da Pós, da FMVZ e FZEA, Estelinha, Rafael, Lílian, Riquelme, Francine, Luis Felipe, Paulinha, Carolzinha, Daniel (Emu), Flávio (Tenébrio), Fernanda, Vinícius, Willian, Ariana, Samuel, Walter, Pascoal, Zé (Mineiro)...

A todos os estagiários, em especial, Ligia, Lívia, Thieska, Luciana e Fernando.

Aos meus "irmãos" no mestrado, Marco, Waleska, Alessandra, Renata, laçanã e Ana Maria, com os quais convivi e aprendi.

Aos potros Veloz, Vivo, Virtual e Vico. 


\section{RESUMO}

RIBEIRO, R. M. Inclusão de Gordura na Alimentação de Eqüinos. [Inclusion of Fat in Equine Diet]. 2007. 68 f. Dissertação (Mestrado em Medicina Veterinária) Faculdade de Medicina Veterinária e Zootecnia da Universidade de São Paulo, São Paulo, 2007.

Com a utilização de quatro potros, com a idade entre 13 a 16 meses, e peso médio de $288 \pm 7,68 \mathrm{Kg}$, recebendo dieta composta de feno de gramínea e concentrado, objetivando-se analisar o efeito da inclusão de diferentes tipos de gordura de origem animal, de origem vegetal e óleo mineral. Avaliou-se a aceitabilidade das dietas, o coeficiente de digestibilidade aparente da Matéria Seca, Matéria Orgânica, Proteína Bruta, Extrato Etéreo, Fibra insolúvel em Detergente Neutro e Fibra insolúvel em Detergente Ácido, utilizando a metodologia de coleta total de fezes, foi observado o efeito da suplementação sobre níveis de gorduras nos valores plasmáticas (Triglicérides, Colesterol e de suas frações VLDL-C, HDL-C, LDL-C). O delineamento experimental utilizado foi o Quadrado Latino 4X4, para separar os efeitos de tratamento foram utilizados três contrastes ortogonais, C1: óleo mineral vs dieta controle; C2: gordura animal vs gordura vegetal e C3: gordura animal+ gordura vegetal vs dieta controle. Os resultados demonstrados nesse experimento foram que a aceitabilidade não foi observada diferença entre os tratamentos, que o contraste ortogonal $\mathrm{C} 1$ apresentou resultado significativo para digestibilidade de MS e MO e EE, e o contraste C3 apresentou valor significativo para EE, para os valores plasmáticos o contraste ortogonal $\mathrm{C} 1$ apresentou valor significativo para HDL-C, sendo que os outros contrastes não apresentaram variação estatística. Podemos concluir que a adição de óleo mineral afeta a digestibilidade da MS, MO e EE se comparado ao controle, não afetando a digestibilidade da PB, FDN e FDA, que a adição de gordura vegetal não se diferencia com a gordura animal quanto a digestibilidade dos nutrientes aqui mensurados e a adição de gordura vegetal e animal altera a digestibilidade do EE em comparação com o controle. Quanto aos valores plasmáticos observamos que a adição de óleo mineral alterou os valores de HDL-C em relação à dieta controle, e os outros contrastes não obtiveram resultados significativos em relação aos valores plasmáticos.

Palavras-chaves: Aceitabilidade. Colesterol. Digestibilidade. Eqüinos. Lipídios, 


\section{ABSTRACTS}

RIBEIRO, R. M. Inclusion of Fat in Equine Diet. [Inclusão de Gordura na Alimentação de Eqüinos]. 2007. 68 f. Dissertação (Mestrado em Medicina Veterinária) - Faculdade de Medicina Veterinária e Zootecnia da Universidade de São Paulo, São Paulo, 2007.

Four foals, aging from 13 to 16 months and with average weight of $288 \pm 7.68 \mathrm{~kg}$ were used in this study, in order to evaluate the effects of the inclusion of different types of fat from animal source, vegetable fat and mineral oil. The basis of the diet of experimental animals was grass hay and concentrate. It was evaluated the acceptability of the diets, the coefficient of apparent digestibility of Dry Material (DM), Organic Matter (OM), Crude Protein (CP), Extract Etéreo (EE), Neutral detergent fiber (NDF) and acid detergent fiber (ADF), by means of the methodology of total feces collection. It was also observed the effect of supplementation on levels of plasma fat (Triglycerides, Cholesterol and its fractions, VLDL-C, HDL-C, LDL-C). The experimental design was a 4X4 Latin Square; three orthogonal contrasts were carried out in order to evaluate the effects of treatments: $\mathrm{C} 1$ : mineral oil vs control diet; $\mathrm{C} 2$ : animal fat vs. vegetable fat and C3: animal fat + vs vegetable fat diet control. It was demonstrated that the acceptability did not differ between treatments; contrast $\mathrm{C} 1$ showed significant results for digestibility of MS and MO and EE, and the contrast C3 showed significant result for EE. In regard of the values of plasma fat, contrast $\mathrm{C} 1$ presented significant value for HDL-C; contrast C2 and C3 did not show statistically significant variation. In conclusion, the addition of mineral oil affected the digestibility of DM, OM and EE, but did not affect the digestibility of CB, NDF and ADF; the addition of vegetable fats did not produce any variation in comparison with animal fats on the digestibility of the measured nutrients and the addition of both vegetable and animal fat altered the digestibility of EE. It was also observed that the addition of mineral oil changed the values of HDL-C compared with the control diet, and either contrasts $\mathrm{C} 1$ or $\mathrm{C} 2$ did not show significant differences on levels of plasma fat.

Key Words: Acceptability. Cholesterol. Digestibility. Equine. Lipids. Triglycerides. 


\section{LISTA DE FIGURAS}

Figura 1 - Coeficiente de digestibilidade aparente da Matéria Seca (CDAMS) e Matéria Orgânica (MO) em \%, de todas as fontes mais o controle com o Desvio Padrão......

Figura 2 - Coeficiente de digestibilidade aparente da Proteína Bruta (CDAPB) em \%, de todas as fontes mais o controle com o Desvio Padrão

Figura 3 - Coeficiente de digestibilidade aparente do Estrato Etéreo (CDAEE) em \%, de todas as fontes mais o controle com o Desvio Padrão.

Figura 4 - Coeficiente de digestibilidade aparente da Fibra Detergente Neutra (CDAFDN) e Fibra Detergente Ácida (CDAFDA) em \%, de todas as fontes mais o Controle com o Desvio Padrão

Figura 5 - Concentrações plasmáticas de Triglicérides dos animais que consumiram as três fontes mais o controle com Desvio Padrão .53

Figura 6 - Concentrações plasmáticas de Colesterol, HDL, LDL e VLDL dos animais que consumiram as três fontes mais o controle com o Desvio Padrão 


\section{LISTA DE TABELAS}

Tabela 1 - Ácidos Graxos Dietéticos

Tabela 2 - Composição de diversas gorduras entre ácidos graxos saturados e insaturados

Tabela 3 - Composição bromatológica do concentrado e do feno experimenta

Tabela 4 - Delineamento quadrado latino para esse experimento 30

Tabela 5 - Valores das quantidades de ração, feno e óleo para cada tratamento.

Tabela 6 - Níveis dos nutrientes das dietas fornecidas aos animais no experimento

Tabela 7 - Esquema de análise de variância para delineamento em Quadrado latino

Tabela 8 - Coeficientes de digestibilidade aparente da matéria seca (CDAMS), matéria orgânica (CDAMO), proteína bruta (CDAPB), extrato etéreo (CDAEE), fibra em detergente neutro (CDAFDN), fibra em detergente ácido (CDAFDA), seus respectivos valores de $\mathrm{P}$ e desvio padrão, para os tratamentos testados

Tabela 9 - Resultados bioquímicos plasmáticos das três fontes mais 0 controle de Colesterol, HDL-C, LDL-C, VLDL-C e triglicérides 


\section{LISTA DE ABREVIAÇÕES}

AGCL - Ácidos Graxos de Cadeia Longa

CDAEE - Coeficiente de Digestibilidade Aparente do Estrato Etéreo

CDAFB - Coeficiente de Digestibilidade Aparente da Fibra Bruta

CDAFDA - Coeficiente de Digestibilidade Aparente Fibra em Detergente Ácido

CDAFDN - Coeficiente de Digestibilidade Aparente Fibra em Detergente Neutro

CDAMM - Coeficiente de Digestibilidade Aparente da Matéria Mineral

CDAMO - Coeficiente de Digestibilidade Aparente da Matéria Original

CDAMS - Coeficiente de digestibilidade Aparente de Matéria Seca

CDAPB - Coeficiente de Digestibilidade Aparente da Proteína Bruta

C - Controle

$\mathrm{COL}$ - Colesterol

EE - $\quad$ Extrato etéreo

FB - Fibra bruta

FDA - $\quad$ Fibra em detergente neutro

FDN - $\quad$ Fibra em detergente ácido

GA - Gordura Animal

GV - Gordura Vegetal

HDL - $\quad$ Lipoproteínas de alta densidade.

LDL - $\quad$ Lipoproteínas de baixa densidade.

LP - L L Lipoproteína

MM - Matéria mineral

MO - Matéria Original

MS - Matéria seca

OM - Óleo Mineral

PB - Proteína Bruta

TG - Triglicerídeos

VLDL - $\quad$ Lipoproteína de muito baixa densidade. 


\section{SUMÁRIO}

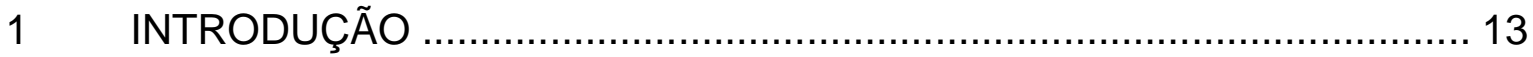

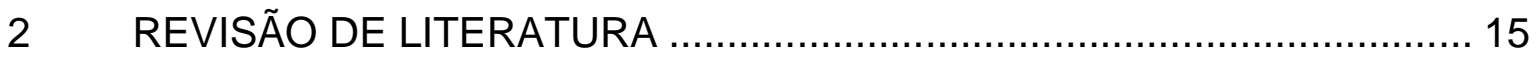

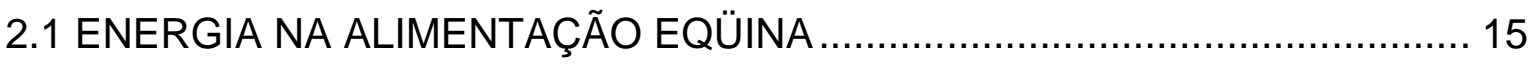

2.2 DIGESTÃO E ABSORÇÃO DE DIETAS COM GORDURA.......................... 17

2.3 LIPOPROTEÍNAS PLASMÁTICAS DOS EQÜINOS …............................... 19

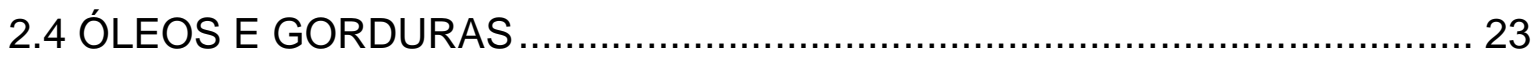

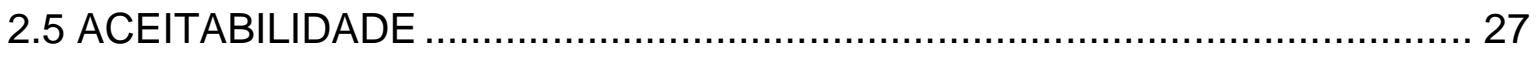

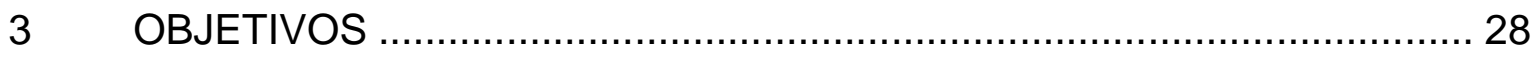

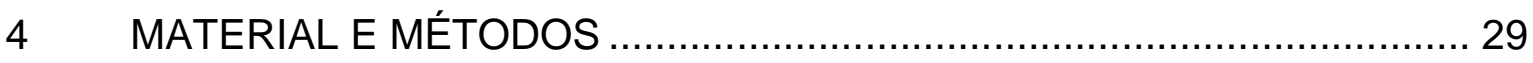

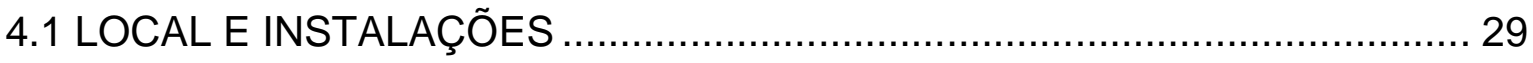

4.2 DELINEAMENTO E TRATAMENTOS EXPERIMENTAIS ............................ 29

4.3 PROCEDIMENTOS PARA DETERMINAÇÃO DA DIGESTIBILIDADE E

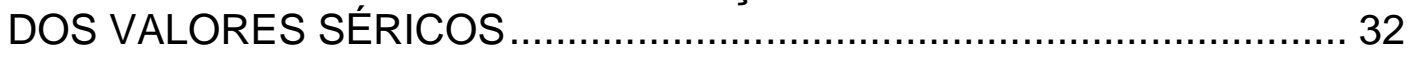

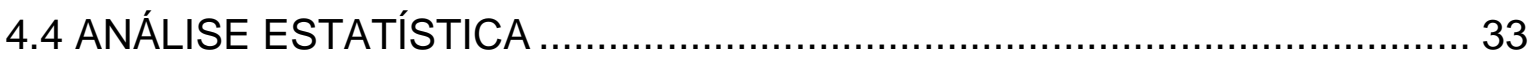

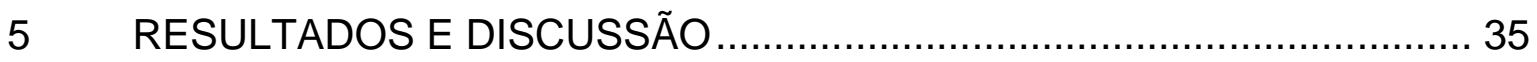

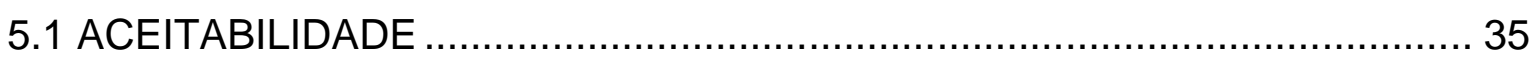

5.2 COEFICIENTE DE DIGESTIBILIDADE APARENTE ................................. 36

5.3 DIGESTIBILIDADE DA MATÉRIA SECA E MATÉRIA ORGÂNICA............... 37

5.4 DIGESTIBILIDADE DA PROTEINA BRUTA …......................................... 41

5.5 DIGESTIBILIDADE DO EXTRATO ETÉREO ............................................. 44

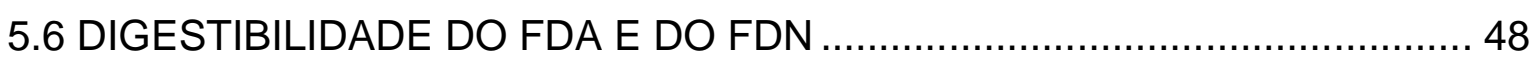

5.7 VALORES BIOQUÍMICOS PLASMÁTICOS .................................................. 52

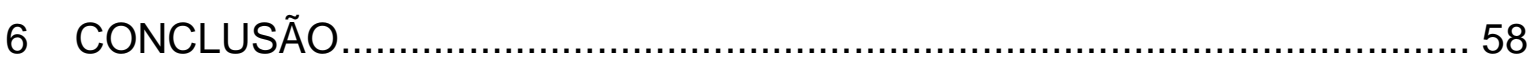

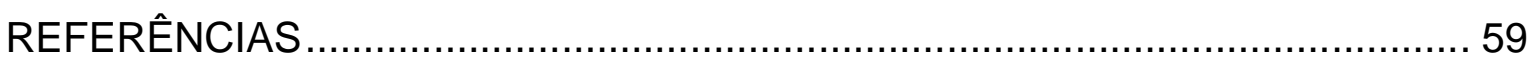




\section{INTRODUÇÃO}

O conhecimento sobre nutrição, fisiologia da digestão e resposta fisiológica a diferentes dietas de eqüídeos tem sido motivo de muitos experimentos. O conhecimento da fisiologia da digestão dos eqüinos, especificamente, é essencial para práticas nutricionais consistentes. É importante conhecer a funcionalidade do aparelho digestivo eqüino e o quão eficiente pode vir a ser. Várias fontes de gorduras ou óleos podem ser utilizadas na alimentação de eqüinos. No entanto, podem ocorrer diferenças quanto a sua aceitabilidade pelos animais (HINTZ, 1983).

Os óleos vegetais são fontes de energia prontamente disponíveis para 0 consumo e, em sua maioria, são alimentos palatáveis para os eqüinos. As gorduras ou óleos são necessários na ração do eqüino para a absorção das vitaminas lipossolúveis: A, D, E e K e como fonte do ácido linoléico (OTT, 1989).

O principal benefício na utilização de gordura no alimento diário é o fornecimento de quantidade de energia quando já se alcançou a taxa máxima de consumo de matéria seca (LAWRENCE, 1990, 1995). Valentine et al. (2001) e Hintz (1999) concordaram que a mudança na dieta de carboidratos para gordura reduziu a severidade dos danos musculares, como rabdmiólise, nos cavalos de esporte. A adição de gorduras em dietas para eqüinos como suprimento de energia em substituição de carboidratos solúveis, tem se mostrado como prática vantajosa.

Dietas com alto teor de carboidratos têm sido associadas com laminite em eqüinos, bovinos e rebanhos de ovelhas. Além disso, a gordura produz um efeito benéfico maximizando a performance em exercícios e treinamentos em competições (MCCANN; MEACHAM; FONTENOR, 1987).

O alto nível de energia encontrado em gorduras e óleos tem estimulado pesquisas que exploram o valor nutricional desses ingredientes na alimentação dos animais de criação. Efeitos benéficos têm sido comprovados na dieta feita com gordura na ração dadas a potros e suínos. Os nutricionistas de eqüinos estão interessados na utilização de gordura a partir de dois pontos de vista. Primeiramente, a utilização de gordura pode ser mais segura em dietas com uma densidade energética alta do que a utilização de carboidratos. Adição de gordura na dieta pode também alterar o metabolismo de energia do animal, reduzindo a 
confiança na glicose, e adicionando o uso de ácidos graxos como origem de energia para os animais (OSAWA; GONÇALVES; RAGAZZI, 2006).

Dois tipos de gordura geralmente são usados para a dieta de eqüinos: o óleo de milho e o óleo de soja. Ambos contêm grande quantidade de amostras de ácido graxos poliinsaturados (SICILIANO; WOOD, 1993).

O óleo mineral, sulfato de sódio (DSS) e sulfato de magnésio são comumente usados como tratamentos laxativos em eqüinos em casos de síndrome cólica, diminuir a absorção de endotoxinas e como protetor de mucosa (BLIKSLAGER, 2005).

A adição de gordura na dieta de animais de alto desempenho tem se tornado comum, pois favorece 0 aumento do balanceamento de energia $e$, conseqüentemente, um maior aporte de energia para o trabalho. Alimento com gordura tem mostrado proteção parcial contra um declínio de glicose no sangue associado com exercícios aeróbicos de longa duração (JULEN et al., 1995).

Existem algumas evidências que comprovam que os desempenhos de cavalos em exercícios melhoraram após um período de alimentação com suplementação de gordura. Dietas com um alto nível de gordura aumentam a capacidade de atletas de oxidarem ácidos graxos. O aumento na capacidade oxidante pode ser benéfico para a musculatura de eqüinos durante o exercício aeróbico (POTTER; WEBB; EVANS, 1992). 


\section{REVISÃO DE LITERATURA}

As gorduras ou óleos podem ser adicionados à ração dos eqüinos para diminuir a poeira; lubrificar e, conseqüentemente, diminuir o desgaste do equipamento de preparação da ração; como ligante para a peletização para evitar a perda de nutrientes; para tentar melhorar a qualidade da pelagem dos animais e para aumento energético da dieta (POTTER; WEBB; EVANS, 1990).

O propósito de aumentar a densidade energética da ração consiste em aumentar o consumo de energia e diminuir o consumo da quantidade de alimento exigido, proporcionando assim as necessidades energéticas para o esporte, a lactação, reprodução, para o crescimento do animal, entre outras finalidades (POTTER; WEBB; EVANS, 1990).

\subsection{ENERGIA NA ALIMENTAÇÃO EQÜINA}

Cavalos com grande demanda nutricional por exemplo: fazendo exercícios, em fase de crescimento, lactantes e ou reprodução necessitam de adição de suplementos na alimentação, ou concentrados (BYRD, 2003).

Segundo a primeira lei da termodinâmica pode-se mudar a energia de uma forma para outra, mas não se pode criá-la e nem destruí-la. A fonte de toda a energia para os seres vivos é a luz solar. Essa energia é capturada pelas plantas, que a usam através da fotossíntese, para trocar o dióxido de carbono (presente no ar) e a água pelo oxigênio e pelos compostos carbônicos que constituem a planta. Esses compostos carbônicos dos vegetais são os carboidratos, as gorduras e junto com o nitrogênio, as proteínas. O nitrogênio (como a pequena quantidade de minerais exigida pelas plantas) é retirado do solo e do ar (PAGAN; HINTZ, 1986).

Os animais consomem as plantas ou os tecidos de outros animais que tenham se alimentado de plantas. As fontes de energia armazenadas (carboidratos, gorduras e proteínas) das plantas são digeridas, absorvidas e transportadas para as células corporais do animal. Algumas dessas fontes são usadas para constituir os componentes estruturais da célula e conseqüentemente no animal; mas, se for 
necessário no futuro, junto com o oxigênio proveniente do ar, elas podem ser convertidas, por meio de reações químicas, a dióxido de carbono e água, produzindo energia no processo. Os animais usam energia para produzir calor e trifosfato de adenosina (ATP), os quais as células usam então para suas funções (HINTZ, 1971).

Competições esportivas requerem uma utilização de alimentos de alto valor energético. O aumento dessa densidade energética é tradicionalmente obtido com o uso de grãos contendo carboidratos. Um excesso de grãos na dieta pode ocasionar redução na ingestão de forragens, levando a diminuição do consumo de água e eletrólitos, aumentado os riscos da ocorrência de doenças principalmente aquelas relacionadas a distúrbios digestivos em cavalos (RESENDE JR et al., 2004).

O que se observa é, principalmente, uma preocupação quanto à adequação dos níveis de energia na dieta, já que esse nutriente pode afetar as outras exigências nutricionais. As principais fontes de energia são os carboidratos e, em segundo, plano as gorduras, que constituem fonte alternativa de energia (RESENDE JR et al., 2004).

O suprimento de energia para atividades físicas com maiores demandas é normalmente obtido pelo aumento do percentual de grãos na dieta. Apesar de constituírem uma fonte concentrada de energia digestível, o aumento do fornecimento de grãos pode conduzir a distúrbios digestivos e metabólicos. Considerando que eqüinos digerem eficientemente dietas que contenham até $30 \%$ da energia digestível sob a forma de gordura, a adição de óleos vegetais ou gordura animal é um excelente meio de aumentar a energia da dieta sem aumentar o volume de alimento (MARQUEZE; KESSLER; BERNARDI, 2001).

Potter; Webb e Evans (1992) relataram que a adição de 5\% ou $10 \%$ de gordura na ração total aumentou a sua densidade de energia metabolizável em 8,5 e $17 \%$ respectivamente, com a diminuição da quantidade de mistura de grãos necessários para manter o peso em 21 e 25\%, sugerindo que essa diminuição no consumo de grãos pode ser benéfica para animais em trabalho, esporte e lactação. Holland (1998), trabalhando com cavalos de sela, concluiu que dietas contento $15 \%$ de óleo de milho são prontamente aceitas pelos cavalos. Segundo Meyer (1995), a administração de até $2,5 \mathrm{~g} / \mathrm{kg} / \mathrm{PV} /$ dia de gordura de boa digestibilidade dividida em várias refeições não resulta em problemas para a saúde dos eqüinos.

Os lipídeos variam em seu valor dietético devido à estrutura química dos triglicerídeos (TG) e dos ácidos graxos de cadeia longa (AGCL). Há também 
desinformação quanto às interações que ocorrem quando eles fazem parte da dieta, o que dificulta tirar conclusões sobre o seu real valor nutritivo (PAGAN; HINTZ, 1986).

O outro fator a ser analisado é o efeito benéfico do uso de gorduras no desempenho de exercício submáximo em esquemas de treinamentos e competições (HAMBLETON et al., 1990; RICH; FONETNOT; MEACHAM, 1981; HICH, 1988).

\subsection{DIGESTÃO E ABSORÇÃO DE DIETAS COM GORDURA}

A maior parte da gordura na dieta está na forma de triglicérides insolúveis em água que são emulsificados por ação dos sais biliares. Grandes glóbulos de gordura são liberados lentamente para dentro do duodeno por causa da inibição por feedback do esvaziamento gástrico pelos lipídeos no duodeno. Assim, o processo de digestão das gorduras leva um tempo maior para ser completado se comparado à digestão de carboidratos e proteínas (SALMAN; KIENZEL; FUHRMANN, 1991).

A digestão dos lipídios no lúmen intestinal requer a participação das secreções pancreática e biliar. A lípase pancreática age na interface óleo e água, das partículas da emulsão, liberando um B-monoglicerídio e dois ácidos graxos livres a partir das posições 1 e 3 do triglicerídio. Estes produtos também são insolúveis em água, mas ocorrem de duas formas: parte polar e hidrossolúvel e parte não-polar e lipossolúvel (PAGAN; HINTZ, 1986).

A solubilização dos produtos finais da digestão pela lípase é dependente da ação dos ácidos biliares. Estes ácidos atuam como um detergente e tornam o material hidrossolúvel em solução formando um agregado com carga negativa denominada micelas. O material hidrossolúvel é dissolvido no interior das micelas. Normalmente, para a formação de uma micela, tem que estar presente no jejuno uma concentração de ácidos biliares de no mínimo $2 \mathrm{mM}$; esta é chamada concentração micelar crítica (ARGENZIO, 1996).

A concentração pós-prandial de ácidos biliares no jejuno proximal é geralmente de pelo menos $4 \mathrm{mM}$ e portanto é mais do que suficiente para promover a solubilização dos lipídios. Na conversão das gorduras a partir de uma emulsão em micelas, o diâmetro da partícula é reduzido 100 vezes e a área superficial aumenta 
mais de 10.000 vezes. As micelas difundem-se desde a partícula de emulsão até a borda em escova do epitélio, onde a gordura é liberada para se difundir através da membrana lipídica para dentro da célula (ARGENZIO, 1996).

A digestão das gorduras ocorre no intestino delgado e a absorção dos ácidos graxos, assim como os monossacarídeos e os diglicerídios ocorrem na região da parte distal do íleo. Os ácidos graxos que não forem absorvidos no intestino delgado vão para o ceco e intestino grosso. A hidrogenação microbiana dos ácidos graxos que não forem absorvidos no intestino delgado ocorre no ceco e intestino grosso (JORGENSEN et al.,1999).

Os ácidos graxos e monoglicerídios são reesterificados para triglicérides dentro do epitélio. Os triglicérides são, então, associados com colesterol, ésteres de colesterol, fosfolipídios e pequenas quantidades de proteína para formar quilomícrons. A formação de quilomícron, que é análogo à micela hidrossolúvel, facilita o transporte de triglicéride insolúvel em água. Sem a camada de proteína, a gordura é incapaz de deixar a célula (POTTER, 1992).

Quando os triglicérides da dieta entram no trato gastrointestinal, e têm contato com as lípases gástricas e intestinais, a solubilização dos ácidos graxos é ressaltada pelos lipídios polares da bile: ácidos biliares e fosfolipídios, nos quais promovem a formação das micelas que solubilizam os ácidos graxos e os mono gliceróis, esses produtos lipídicos passam por difusão mono-celular pelas células da mucosa do intestino delgado. No entanto, pequenas quantidades de ácidos graxos saturados passam pelo trato gastrointestinal sem serem absorvidas. Moléculas de triglicérides que contêm três ácidos graxos saturados são pobres em substratos para lípase pancreática e podem não ser digeridas ou absorvidas, quando há falta de bile, a absorção de gordura é reduzida embora não sendo ausente, quando há ausência de lípase pancreática a hidrólise dos triglicérides são reduzidos e a absorção da gordura é severamente abreviada, pois os triglicerídios são excretados intactos pelas fezes (SCOTT et al., 1993). 


\subsection{LIPOPROTEÍNAS PLASMÁTICAS DOS EQÜINOS}

A gordura da alimentação humana e animal são formados, em sua maior parte, por triglicérides, fosfolipídios, monoglicerídeos e outras substâncias de natureza lipídica, presentes em menores proporções (MARINETTI, 1990; GRUNDY, 1996; PENZ JR.; VIOLA, 1998). Segundo Correa e Correa (1985), as gorduras são triglicérides, compostos de uma molécula de glicerol e três moléculas de ácidos graxos de cadeia longa, que podem ser os mesmos ou diferentes.

Contrariamente aos ácidos graxos de cadeia longa, curta ou volátil, produzidos pela fermentação bacteriana dos carboidratos ingeridos (que contém somente de dois a cinco átomos de carbono), a maioria dos ácidos graxos de cadeia longa das gorduras contém 16 a 20 átomos de carbono. Quanto mais insaturados os ácidos graxos de cadeia longa (quanto maior o número de ligações duplas entre seus átomos de carbono) e menor a extensão da sua cadeia (menos átomos de carbono em sua constituição), mais baixo o ponto de fusão do triglicerídeo. Quando o ponto de fusão dos triglicérides for menor que a temperatura ambiente, este recebe o nome de óleo; quando for maior que a temperatura ambiente, é chamado de gordura (SCOTT et al., 1993).

Os triglicérides são solúveis em solventes orgânicos (éter, por exemplo). Os outros constituintes são minerais dos tecidos vegetais e animais são hidrossolúveis e relativamente insolúveis em solventes orgânicos. Essa diferença constitui a base da extração e determinação da quantidade de lipídeos em uma amostra e a razão nas quais os lipídeos são chamados de extrato etéreo que no caso do alimento dos eqüinos corresponde quase que totalmente a gorduras e óleos (POTTER, 1992).

Depois de consumidas, as gorduras devem ser digeridas, absorvidas e transportadas no organismo. Como as gorduras são insolúveis em água, devem ser transportadas no sangue por meio de substâncias hidrossolúveis denominadas lipoproteínas (LP) (PAGAN; HINTZ, 1986).

Segundo Correa e Correa (1985) as LP são esféricas com lipídios neutros (triglicérides e ésteres de colesterol) com fosfolipídios e colesterol associados com apoproteínas, nos animais monogástricos e poligástricos os lipídios séricos diminuem antes do parto e depois começam a aumentar mesmo no período da amamentação. Estas lipoproteínas são classificadas de acordo com sua densidade e 
incluem lipoproteínas de muito baixa densidade (VLDL); lipoproteínas de baixa densidade (LDL) e lipoproteínas de alta densidade (HDL). As albuminas, ainda não pertencendo ao grupo das lipoproteínas, são incluídas como transportadoras de ácidos graxos no sangue.

Os lipídios no plasma sanguíneo são originários de absorção intestinal, mobilização de reserva do tecido adiposo ou processos sintéticos. A maioria dos lipídeos plasmáticos são encontrados como um complexo de ácido graxo e albumina (SCOTT et al., 1993).

No processo de absorção de lipídios da dieta ou endógenos no trato gastrointestinal, se procede pelos vasos lacteais como quilomícrons, que aparece no plasma após refeições ricas com gordura (CORREA; CORREA, 1985), junto com alguma lipoproteína de densidade baixa (VLDL). Esses complexos são formados nas células mucosas intestinais e são formados em grande parte por um núcleo central de triagliceróis contendo ésteres de colesterol e um pouco de colesterol livre, enquanto que os envoltórios dessa lipoproteína contem fosfolipídios mais certa quantidade de proteína e colesterol livre. A linfa transportando essas lipoproteínas de origem intestinal entra no sangue sistêmico através do ducto linfático torácico. Os ácidos graxos de cadeia curta e média e o glicerol livre resultante da hidrólise completa de triacilgliceróis na luz intestinal são absorvidos no sangue porta e desse modo são conduzidos diretamente ao fígado (MEYERS, 1989).

Os lipídios, dependendo de sua composição, são primordialmente degradados e absorvidos no intestino delgado, sua digestibilidade alcança $90 \%$ ou mais e é maior em gorduras com ponto de fusão baixo, tais como óleos vegetais. Para que grandes quantidades de gorduras sejam empregadas na ração, como por exemplo no caso de animais atletas, é necessário que estas sejam altamente digestíveis, pois sua passagem ao intestino grosso pode levar à inibição da flora microbiana cecal (MEYER, 1995).

No isolamento e caracterização as lipoproteínas plasmáticas eqüinas, foram reportadas que a HDL responde pôr $61 \%$ do perfil de lipoproteínas (LP) no cavalo, a VLDL pôr $24 \%$ e a LDL pôr 15\%. A VDLP é considerada a principal transportadora plasmática de triglicérides no cavalo (MARCHELLO et al., 2000). Em humanos, o sistema de lipoproteínas é utilizado para detectar algumas doenças e desordens nutricionais. Estudos que isolaram e calcularam LP em cavalos só avaliaram cavalos alimentados com dietas tradicionais. Poucos autores fizeram trabalhos para avaliar 
LP em cavalos alimentados com dietas com alto teor de gordura, entre eles podemos citar Geelen (2001) que demonstrou que dietas ricas em gorduras elevaram a atividade da lipoproteína lipase, assim como provoca uma diminuição na concentração de triglicérides plasmáticos.

De acordo com Ferrante e Kronfeld (1992) eqüinos alimentados com ração rica em lipídios durante um período de 30 dias apresentaram teores de glicogênio normais, no entanto os teores de glicogênio aumentam com quantidades crescentes de gorduras adicionadas em até $12 \%$ da ração total, porém segundo Hambleton et al. (1990) e Oldham et al. (1990) não aumentaram adicionalmente e começou a diminuir com níveis de 15 a 20 \% de gorduras adicionadas a ração total.

Contudo, Marchello et al. (2000) relataram que o fígado aparentemente adapta-se a quantidades maiores de lipídios na dieta produzindo maiores níveis de bile. A bile é composta principalmente de sais biliares, que são derivadas do colesterol. Para poder aumentar a produção de bile, uma maior quantidade de colesterol endógeno deve ser absorvida no processo digestivo. Isto ficaria evidenciado pelo aumento dos níveis de colesterol nas frações de LDL e HDL dos cavalos alimentados com dietas ricas em gorduras. Como as gorduras dessas dietas foram principalmente à base de óleo de milho pode-se descartar a presença de colesterol exógeno, razão pela qual a elevação do colesterol plasmático pode ser atribuída a um aumento na produção endógena do mesmo, estimulada pelo aumento na ingestão de gordura. No caso, as concentrações de triglicérides e colesterol sérico foram mais elevadas nas amostras sangüíneas daqueles cavalos submetidos a uma dieta rica em gorduras, mas foram muito variáveis.

Segundo Marchello et al. (2000) afirmam que as variações nas concentrações de lipídios séricos devem-se a uma variação no tempo de tomada de amostra durante o dia. Para padronizar este tempo de tomada de amostras foi feito o ensaio seguinte: depois de uma amostra inicial, uma série de amostras sangüíneas póspandriais foram tomadas com intervalos de uma hora, durante 8 horas, depois de analisar os dados, a hora três pós-refeição foi escolhida para representar o valor das LP pós-prandiais.

De acordo com Kurcz et al. (1991) a suplementação com gordura não surte efeito aparente nos vários parâmetros sanguíneos incluindo os hematócritos, as concentrações de hemoglobina, proteína total, cálcio, fósforo, magnésio, sódio e 
lactato, porém aumentou a concentração plasmática de colesterol, principalmente a fração protéica de alta densidade (HDL).

Em um estudo de Bowman, Fontenot e Weeb (1977) a concentração plasmática de colesterol aumentou de 122 para $155 \mathrm{mg} / \mathrm{dl}$ a medida em que se aumentou a adição de gordura na ração de 0 (zero) para 20\%. Estudos de Kurcz et al. (1993) demonstraram que a suplementação com gordura aumenta a fração de triglicérides VLDL em eqüinos durante períodos de 3 a 7 horas pós - prandiais.

Allan et al. (2001) trabalharam com gordura de leite, óleo de peixe, azeite de oliva e gordura de coco, todos no nível de $4 \%$ e encontraram uma série de diferenças no colesterol total e nas lipoproteínas. Inclusive resultados que reforçam o fato de haver diferenças importantes no metabolismo de lipoproteínas entre o suíno e o homem, como por exemplo, o aumento significativo nos níveis de colesterol em HDL em animais que receberam gordura de coco, azeite de oliva ou gordura de leite em comparação com os que receberam dieta controle ou contendo óleo de peixe. Fato semelhante foi observado por Pimenta et al. (2001) que obteveram um efeito quadrático para colesterol total e colesterol em LDL em leitões alimentados com diferentes níveis de gordura de coco.

Segundo Bruss (1980) os valores médios de colesterol total e de triglicérides total encontrados em eqüinos são, respectivamente, entre 75 a $150 \mathrm{mg} / \mathrm{dL}$ e de 4 a $44 \mathrm{mg} / \mathrm{dL}$, segundo Yamamoto, Tanaka e Sugano (1979) os valores médios totais de LDL variam entre 24,63 e $38,87 \mathrm{mg} / \mathrm{dL}$, para HDL os valores médios totais são entre 52,20 e $62,26 \mathrm{mg} / \mathrm{dL}$ e para VLDL os valores médios totais são entre 0,77 a 3,09 $\mathrm{mg} / \mathrm{dL}$ Discordando desses dados Watson; Packard (1999) relatam em seu experimento valores médios totais de LDL entre 15,47 e $31,71 \mathrm{mg} / \mathrm{dL}$ e de HDL entre 44,8 e $58,78 \mathrm{mg} / \mathrm{dL}$ 


\section{4 ÓLEOS E GORDURAS}

O alto conteúdo energético das gorduras e óleos tem estimulado diversas pesquisas destinadas a conhecer melhor o valor alimentício destes ingredientes (MCCANN; MEACHAM; FONTENOT, 1987).

$\mathrm{Na}$ composição química dos óleos e gorduras vegetais encontram-se traços de hidrocarbonetos, ceras, esteróides, vitaminas e alguns outros compostos. As frações majoritárias, que corresponde a uma faixa de 85 a $95 \%$ do total dos componentes presentes nos óleos e gorduras, é dada pelos triglicérides. Isto faz com que as propriedades de um óleo ou gordura sejam diretamente dependentes de sua composição de triglicérides. As misturas triacilglicerídicas sólidas à temperatura ambiente são referidas como gorduras, e as líquidas são usualmente denominadas de óleos (FILHO, 1995).

Os triglicérides são compostos por 3 moléculas de ácidos graxos esterificados com 1 molécula de glicerol, são derivados de fontes naturais (gordura animal e vegetal) e fontes modificadas industrialmente para alimentos especiais. Os ácidos graxos são classificados mediante ao número de cadeia dupla de carbono e sua extensão das cadeias. Os ácidos graxos são classificados tipicamente em 3 grupos: saturados, monossaturados e poliinssaturados (GRUNDY, 1996).

Os ácidos graxos saturados não apresentam duplas ou triplas ligações na molécula, tendo como fórmula geral $\left(\mathrm{C}_{16} \mathrm{H}_{32} \mathrm{O}_{2}\right)$. Normalmente possuem ponto de fusão elevado, sendo sólidos em temperatura ambiente. Ácidos graxos insaturados possuem como fórmula geral $\mathrm{C}_{n} \mathrm{H}_{2 n-2 x} \mathrm{O}_{2}$, onde $\mathrm{O} x$ é o número de insaturações. Normalmente possuem ponto de fusões baixo, apresentando assim forma líquida em temperatura ambiente (FERREIRA et al., 1998).

O comprimento da cadeia dos ácidos graxos é de 8 a 18 átomos de carbonos, dois exemplos de ácidos graxos saturados são o ácido palmítico (16:0) e ácido esteriático (18:0), o primeiro número dentro do parêntese é referente ao número de átomos de carbono, e o segundo referente ao número de duplas ligações. Os ácidos graxos monossaturados possuem apenas uma ligação dupla sendo exemplo o ácido oléico (cis-18:1n-9), em que o termo "cis" indica ligação dupla em configuração cis, e o termo 1n-9 indicam que a ligação dupla é locada no 9o átomo de carbono, os ácidos graxos poliinssaturados possuem uma ou duas ligações duplas, sendo que 0 
ácido graxo poliinssaturados mais predominante é o ácido linoléico (18:3n-3), e o ácido linolênico (18:3n-3) (GRUNDY, 1996).

Tabela 1 - Ácidos Graxos Dietéticos

\section{Ácidos Graxos Saturados}

\begin{tabular}{l|l}
\hline Ácido Esteriático & $(18: 0)$ \\
Ácido Palomitico & $(16: 0)$ \\
Ácido Myristico & $(14: 0)$ \\
Ácido Lairico & $(12: 0)$ \\
\hline Ácido Graxo Monossaturado & \\
\hline Ácido oléico & (cis-18:1) \\
Ácido elaidico & (trans -18:1) \\
\hline Ácido Graxo Poliinssaturado & \\
\hline Ácido graxo n-6 & \\
\hline Ácido Linoléico & $(18: 2)$ \\
\hline Ácido graxo n-3 & \\
\hline Ácido linolênico & $(18: 3)$ \\
\hline
\end{tabular}

Fonte: (GRUNDY, 1996).

O primeiro número indica o número de átomos de carbono; e o segundo dígito é o número de duplas ligações por moléculas.

O valor alimentício, isto é, energético de todo o ácido graxo é praticamente igual. Existem, entretanto, diferenças entre eles quanto ao seu efeito fisiológico. Alguns dos ácidos graxos insaturados, os chamados ácidos graxos essenciais, produzem efeito especial no organismo vivo (TURATTI; GOMES; ATHIE, 2002).

De acordo com Mandarino (1995) e Moretto e Fett (1998), Turatti, Gomes e Athie (2002), as fontes de ácidos graxos na dieta humana são: gordura com altos teores de ácidos graxos saturados como manteiga, gorduras láuricas (coco babaçu, palmiste e copra), banha de porco e sebo bovino; óleos com altos teores de ácidos graxos saturados como polpa de palma (dendê), algodão; óleos com altos teores de ácidos graxos monoinsaturados, principalmente oléico como oliva, canola, amendoim, arroz; óleos com altos teores de ácidos graxos poliinsaturados, principalmente linoléico como girassol, milho, soja, açafrão, entre outros. 
Tabela 2 - Composição de diversas gorduras entre ácidos graxos saturados e insaturados

\begin{tabular}{cccccccccc}
\hline \multicolumn{1}{c}{ Óleos e Gorduras } & $\mathbf{1 2 : 0 0}$ & $\mathbf{1 4 : 0 0}$ & $\mathbf{1 6 : 0 0}$ & $\mathbf{1 6 : 0 1}$ & $\mathbf{1 8 : 0 0}$ & $\mathbf{1 8 : 0 1}$ & $\mathbf{1 8 : 0 2}$ & $\mathbf{1 8 : 0 3}$ & Outros \\
\hline \multicolumn{8}{c}{ Gorduras com Ácidos Graxos Saturados } \\
\hline Óleo de Palma & 49,6 & 16,0 & 8,0 & - & 2,4 & 13,7 & 2,0 & - & 0,1 \\
Gordura Bovina & 0,1 & 3,3 & 25,5 & 3,4 & 21,6 & 38,7 & 2,2 & 0,6 & 4,6 \\
Gordura Suína & 0,1 & 1,5 & 24,8 & 3,1 & 12,3 & 45,1 & 9,9 & 1,1 & 3 \\
Gordura de frango & 0,2 & 1,3 & 23,2 & 6,5 & 6,4 & 41,6 & 18,9 & 1,3 & 0,6 \\
Óleo de Coco & 48,5 & 17,6 & 8,4 & - & 2,5 & 6,5 & 1,5 & - & 0,1 \\
\hline \multicolumn{8}{c}{ Gorduras com Ácidos Graxos Insaturados } \\
\hline \multicolumn{7}{c}{ Ácido Oléico } \\
\hline Óleo de Oliva & - & 13,7 & - & 2,5 & 71,1 & 10,0 & 0,6 & 2,1 \\
Óleo de Canola & - & 3,9 & - & 1,9 & 64,1 & 18,7 & 9,2 & 2,2 \\
Óleo de Amendoim & 0,3 & 11,6 & - & 3,1 & 46,5 & 31,4 & 1,5 & 5,8 \\
Óleo de Girassol & 0,1 & 5,5 & - & 2,2 & 79,7 & 12 & 0,2 & 0,3 \\
\hline \multicolumn{7}{c}{ Ácido Linolêico } \\
\hline Óleo de Milho & - & 12,2 & - & 2,2 & 27,5 & 57 & 0,9 & 0,2 \\
Óleo de Algodão & 0,9 & 24,7 & - & 2,3 & 17,6 & 53,3 & 0,3 & 0,9 \\
Óleo de Aveia & 0,2 & 17,1 & - & 1,4 & 33,4 & 44,8 & 0,2 & 2,9 \\
Óleo de Soja & 0,1 & 11,0 & - & 4,0 & 23,4 & 53,2 & 7,8 & 0,5 \\
\hline
\end{tabular}

Fonte: (GRUNDY, 1996).

Os valores são em \% do total de ácidos graxos

O óleo de soja é geralmente extraído com solventes orgânicos e apresenta cor amarela intensa. Sua principal utilização é como óleo comestível e frituras, mas também é amplamente usado na fabricação de margarinas, sabonetes e sabões (CORREA, 1984). Contém $38,72 \%$ de ácido linoléico contra $11,47 \%$ de ácido linolênico (MACHADO; FONTES, 2002).

A semente mais estudada atualmente é a de linhaça, sendo a espécie mais rica em ômega-3, praticamente constituída em sua totalidade por ácido linolênico (C18:3 n-3). A semente de linhaça contém aproximadamente 35\% de lipídios totais, dos quais 50\% são representados pelo ácido linolênico (MORI, 2001). A linhaça é uma das oleaginosas tradicionais com história, por causa da utilização de suas fibras em produtos têxteis, e também porque o óleo obtido a partir de sua semente possui um alto teor de ácido linolênico, sendo que as tortas obtidas podem ser utilizadas para balanceamento de ração animal (TURATTI; GOMES; ATHIE, 2002).

Sendo uma das fontes mais concentradas de ácidos graxos poliinsaturados, especialmente de linolênico (LNA), e seu óleo contendo de 50-55\% de linolênico, é biologicamente precursor dos ácidos eicosapentaenóico (EPA), docosapentaenóico (DPA) e docosahexaenóico (DHA), através de processos de dessaturação e 
elongamento (MAZALLI, 2000).

O sebo suíno caracteriza-se por apresentar em sua composição 43\% de ácido oléico, $23 \%$ de ácido palmítico e $13 \%$ de esteárico. O óleo mineral é culturalmente utilizado com laxativo em seres humanos, não havendo um esclarecimento científico sobre seu efeito em eqüinos (TURATTI; GOMES; ATHIE, 2002).

Segundo Jorgensen, Jakobsen e Egcum (1992), a gordura animal fornecida na dieta tem baixa digestibilidade e baixo valor energético se comparado com a gordura vegetal, devido a um índice mais elevado de ácidos graxos saturados. Os ácidos graxos saturados podem ter uma menor absorção ileal se comparados com os ácidos graxos insaturados que são encontrados nos óleos vegetais. Dependendo do grau de saturação os ácidos graxos podem ter diferentes velocidades de absorção (JORGENSEN; JAKOBSEN; EGCUM, 1992, 1993, OVERLAND; MROZ; SUNDSTOL, 1994).

O óleo mineral pode ser classificado como catártico emoliente ou lubrificante, que lubrifica e amolece as fezes, impedindo assim a dessecação das fezes exercendo efeito laxante, sendo que junto com o óleo mineral pode ser classificado como catártico os óleos vegetais e os docusatos. O óleo mineral (parafina líquida, vaselina líquida ou óleo de parafina) é uma mistura de hidrocarbonetos líquidos obtidos do petróleo, quando administrado por via oral não é digerido e praticamente não é absorvido pelo organismo. Quando usado por 2 a 3 dias o óleo penetra nas fezes, amolecendo-as, e por recobrir a mucosa intestinal pode reduzir a absorção de água (SPINOSA, 1999).

Segundo Andrade et al. (2002) os óleos minerais lubrificam as fezes e a mucosa intestinal, favorecendo a eliminação do bolo fecal sem aumentar o peristaltismo, o uso prolongado pode resultar em acúmulo de óleo em nódulos linfáticos e deficiência de vitaminas lipossolúveis, podem ser fornecidos por via oral ou retal. Quando fornecido por via oral para uso clínico a vaselina ou glicerina devem ser usados com água morna na proporção de 1:1.

O óleo mineral é administrado em cavalos com sinais indicativos de impactação do cólon maior, mas pode também ser administrado em casos de sintomas clínicos de cólica, tentando assim prevenir o inicio de uma impactação potencial que não encontrada durante a palpação retal. Óleo mineral é muito usado como marcador de trânsito gastrointestinal já que se encontra presente no ânus e na cauda 18 horas depois de fornecido para o animal (BLIKSLAGER, 2005). 


\subsection{ACEITABILIDADE}

Várias Dietas com gorduras podem se oferecidas aos eqüinos, no entanto suas repostas se diferenciam quanto a sua palatabilidade. Em geral os cavalos não aceitam as gorduras, segundo Holland (1998) em um experimento com 10 diferentes tipos de gordura, ocorreu uma preferência para o óleo de milho. Outros tipos de óleos vegetais também são bem aceitos por esses animais, por exemplo, o óleo de coco. A palatabilidade pode ser um problema quando a gordura é oferecida em uma quantidade grande em um espaço de tempo curto, o correto é oferecer pequenas quantidades em forma gradativas e dividido em várias porções diárias (GEELEN, 2001).

Bowman, Fontenot e Webb (1977), estudando 10 tipos de óleos e misturas diferentes de gorduras dadas em dietas a eqüinos, concluiu que eqüinos tem predileção por óleo de milho sendo bem aceito por cavalos em níveis que variam de 10 a 30\% da matéria seca, mas a aceitabilidade de outras gorduras não está bem estabelecida e tem sido questionada. Gordura animal não são tão puras quando comparadas a óleos vegetais, sendo talvez esta razão de sua aceitabilidade e densidade energética serem menores.

Holland et al. (1996) determinaram que dietas com teores de 15\% de óleo de milho são muito bem aceitas por eqüinos, porém analisando o uso de lecitinas nas dietas de eqüinos, concluiu-se que essas substâncias diminuem a aceitabilidade dos óleos de soja e milho. 


\section{OBJETIVOS}

O objetivo desse experimento foi avaliar o efeito da inclusão de duas diferentes fontes de gordura, óleo vegetal e gordura animal e, o efeito do óleo mineral, adicionadas a dieta de eqüinos; sobre a aceitabilidade, o coeficiente de digestibilidade aparente da MS, MO, MM, PB, EE, FDN e FDA e nos valores plasmáticos de Triglicérides, Colesterol, HDL-C, LDL-C e VLDL-C. 


\section{MATERIAL E MÉTODO}

Os materiais e as metodologias utilizados neste experimento estão descritos nos itens que seguem.

\subsection{LOCAL E INSTALAÇÕES}

O experimento foi conduzido nas instalações do Setor de Eqüideocultura do Campus Administrativo de Pirassununga da Universidade de São Paulo (USP), as análises de digestibilidade foram efetuadas nos laboratórios do Departamento de Nutrição e Produção Animal da Faculdade de Medicina Veterinária e Zootecnia da Universidade de São Paulo (FMVZ) e as análises bioquímicas plasmáticas no Laboratório particular São Judas, situados no município de Pirassununga, estado de São Paulo.

\subsection{DELINEAMENTO E TRATAMENTOS EXPERIMENTAIS}

Foram utilizados quatro potros, filhos do mesmo garanhão, com idade média de 13 a 16 meses e peso médio de $288 \pm 7,68 \mathrm{~kg}$, pulverizados contra ectoparasitos, imunizados contra tétano e vermifugados, alojados em baias individuais devidamente identificadas, forradas com serragem de madeira.

Durante o período experimental, a água e sal mineralizado foram oferecidos ad libitum, seguindo as recomendações estabelecidas no Equine Nutrient Requeriments, NRC (1989), para eqüinos nesta categoria nutricional. Os animais foram alimentados com feno de gramínea Cynodon dactylon (L.) Pers.Var. "Coast cross", e concentrado experimental, com a seguinte composição: $25 \%$ de Soja Extrusado, $60 \%$ de Rolão de Milho, 10\% de Fubá de Milho, 4\% de núcleo mineral e $1 \%$ de sal comum, com os seguintes valores bromatológicos: 
Tabela 3 - Composição bromatológica do concentrado e do feno experimental

\begin{tabular}{cccc}
\hline Nutrientes (\%) & Concentrado & Feno & Óleo e Gordura \\
\hline MS & 90,37 & 92,64 & 100 \\
MM & 7,24 & 5,48 & - \\
PB & 14,02 & 13,85 & - \\
EE & 4,66 & 1,43 & 99,9 \\
FDA & 12,37 & 38,98 & - \\
FDN & 19,9 & 80,38 & - \\
Ca & 1,9 & 0,29 & - \\
P & 0,61 & 0,2 & - \\
\hline
\end{tabular}

Foi utilizado o delineamento experimental em Quadrado Latino 4X4 (4 animais, 4 tratamento e 4 repetições) para separar os efeitos dos tratamentos foram utilizados 3 contrastes ortogonais .

Tabela 4 - Delineamento quadrado latino para esse experimento

\begin{tabular}{|c|c|c|c|c|}
\hline $\begin{array}{l}\text { Animal } \\
\text { Período }\end{array}$ & Veloz & Vivo & Virtual & Vico \\
\hline I & Controle & $\begin{array}{l}\text { Óleo de } \\
\text { Soja }\end{array}$ & $\begin{array}{c}\text { Gordura } \\
\text { Animal }\end{array}$ & $\begin{array}{c}\text { Óleo } \\
\text { Mineral }\end{array}$ \\
\hline II & $\begin{array}{c}\text { Óleo de } \\
\text { Soja }\end{array}$ & $\begin{array}{c}\text { Gordura } \\
\text { Animal }\end{array}$ & $\begin{array}{c}\text { Óleo } \\
\text { Mineral }\end{array}$ & Controle \\
\hline III & $\begin{array}{c}\text { Óleo } \\
\text { Mineral }\end{array}$ & Controle & $\begin{array}{c}\text { Óleo de } \\
\text { Soja }\end{array}$ & $\begin{array}{c}\text { Gordura } \\
\text { Animal }\end{array}$ \\
\hline IV & $\begin{array}{c}\text { Gordura } \\
\text { Animal }\end{array}$ & $\begin{array}{c}\text { Óleo } \\
\text { Mineral }\end{array}$ & Controle & $\begin{array}{c}\text { Óleo de } \\
\text { Soja }\end{array}$ \\
\hline
\end{tabular}


Tabela 5 - Valores das quantidades de ração, feno e óleo para cada tratamento

\begin{tabular}{ccccc}
\hline \multirow{2}{*}{ Ingredientes (g/dia) } & \multicolumn{4}{c}{ Dieta } \\
\cline { 2 - 5 } & Controle & $\begin{array}{c}\text { Óleo } \\
\text { vegetal }\end{array}$ & $\begin{array}{c}\text { Gordura } \\
\text { animal }\end{array}$ & $\begin{array}{c}\text { Óleo } \\
\text { Mineral }\end{array}$ \\
\hline $\begin{array}{c}\text { Concentrado } \\
\text { experimental }\end{array}$ & 3000 & 3000 & 3000 & 3000 \\
Gordura e Óleo & 0 & 300 & 300 & 300 \\
$\begin{array}{c}\text { Feno de Coastcross } \\
\text { Total }\end{array}$ & 3000 & 3000 & 3000 & 3000 \\
\hline
\end{tabular}

Sendo que os tratamentos diferem entre si apenas na fonte de gordura:

- Tratamento 1: feno + concentrado, sem adição de gordura (controle);

- Tratamento 2: feno + concentrado com $300 \mathrm{~g}$ óleo vegetal;

- Tratamento 3: feno + concentrado com $300 \mathrm{~g}$ gordura animal;

- Tratamento 4: feno + concentrado com $300 \mathrm{~g}$ óleo mineral.

As dietas foram fornecidas em duas refeições diárias, divididas em partes iguais e oferecidas às 7:00 e 19:00 horas, adotando-se o consumo diário individual de $2 \%$ do peso vivo, sendo $50 \%$ concentrado e $50 \%$ volumoso, em cochos separados. Foi adotado um tempo de consumo máximo para o concentrado de uma hora e meia. A duração de cada período foi de 11 dias, sendo 8 de adaptação à dieta e 3 para coleta total de fezes. Os animais foram pesados no início e ao final de cada tratamento.

As matérias primas dos óleos de cada tratamento foram óleo de soja para o óleo vegetal, sebo suíno para a gordura animal e vaselina líquida para óleo mineral, adicionado $10 \%$ em cima do valor da quantidade de ração oferecida para os animais. 
Tabela 6 - Níveis dos nutrientes das dietas fornecidas aos animais no experimento

\begin{tabular}{cccccccccc}
\hline $\begin{array}{c}\text { Consumo de } \\
\text { nutrientes } \\
k g\end{array}$ & \multicolumn{2}{c}{ Controle } & \multicolumn{2}{c}{ Óleo vegetal } & \multicolumn{2}{c}{ Gordura animal } & \multicolumn{2}{c}{ Óleo Mineral } \\
\cline { 2 - 9 } & Concentrado & Feno & Concentrado & Feno & Concentrado & Feno & Concentrado & Feno \\
\hline MS & 2,7111 & 2,7792 & 3,0111 & 2,7792 & 3,0111 & 2,7792 & 3,0111 & 2,7792 \\
PB & 0,4206 & 0,4155 & 0,4206 & 0,4155 & 0,4206 & 0,4155 & 0,4206 & 0,4155 \\
EE & 0,1398 & 0,0429 & 0,4398 & 0,0429 & 0,4398 & 0,0429 & 0,4398 & 0,0429 \\
FDA & 0,3711 & 1,1694 & 0,3711 & 1,1694 & 0,3711 & 1,1694 & 0,3711 & 1,1694 \\
FDN & 0,597 & 2,4114 & 0,597 & 2,4114 & 0,597 & 2,4114 & 0,597 & 2,4114 \\
Cálcio & 0,057 & 0,0087 & 0,057 & 0,0087 & 0,057 & 0,0087 & 0,057 & 0,0087 \\
Fósforo & 0,0183 & 0,006 & 0,0183 & 0,006 & 0,0183 & 0,006 & 0,0183 & 0,006 \\
\hline
\end{tabular}

As sobras dos alimentos foram retiradas diariamente, sendo pesadas, acondicionadas em sacos plásticos e congeladas para posterior análise. Antes do período destinado para a coleta total de fezes foi retirada toda a serragem utilizada como cama nas baias; durante os três dias destinados para coleta das amostras, identificadas individualmente em sacolas de coleta, do total excretado, após homogeneização, foram retirados $5 \%$, sendo acondicionados em sacos plásticos e congelados, para análise bromatológica de MS, MO, PB, EE, FDA, FDN das fezes segundo Silva e Queiroz (1998).

\subsection{PROCEDIMENTOS PARA DETERMINAÇÃO DA DIGESTIBILIDADE E DOS VALORES SÉRICOS}

Ao final do período de coleta, as amostras de fezes totais e das sobras foram descongeladas a temperatura ambiente, homogeneizadas manualmente, pesadas $\mathrm{e}$ secas em estufa de ventilação forçada a $65^{\circ} \mathrm{C}$ por 72 horas. Após o preparo das amostras, as análises bromatológica das dietas e das fezes foram feitas segundo a metodologia de Silva e Queiroz (1998). 
Para Triglicérides, Colesterol, HDL-C, LDL-C e VLDL-C as amostras de sangue foram coletas, após jejum prévio de 12 horas, no final de cada período, através da punção da veia jugular, com agulhas 40×12 em frasco de tubo seco, para então serem encaminhadas ao laboratório.

As diferentes frações foram concentradas através do sistema de filtração pressurizada e analisadas com kits analíticos de colesterol (ANALISA) e triglicérides (ANALISA). Para avaliação da concentração total de lipídios foi aplicado o método de Lowry (1977).

\subsection{ANÁLISE ESTATÍSTICA}

Os resultados foram analisados através do programa computacional Statistical Analysis System (SAS, 2001) sendo anteriormente verificada a normalidade dos resíduos pelo Teste de Shapiro-Wilk (PROC UNIVARIATE) e as variâncias comparadas pelo Teste de Hartley (OTT, 1993). Os dados (variável dependente) que não atenderam a estas premissas foram submetidos à transformação logarítmica $[\log (X+1)]$ ou quadrática $[R Q(X+1 / 2)]$. Os dados originais ou transformados, quando este último procedimento foi necessário, foram submetidos à análise de variância que separou como causas de variação efeito de tratamento e efeito de período, do Tratamento e do Animal (Tabela 7). Os efeitos de tratamento foram separados através de três contrastes ortogonais. Tal análise foi realizada utilizando-se o procedimento General Linear Model (PROC GLM do SAS).

O primeiro contraste ortogonal que vai ser designado como $\mathrm{C}$, foi denominado de efeito da dieta com Óleo mineral vs. Dieta controle, OM vs. C.

O segundo contraste ortogonal que vai ser designado como $\mathrm{C} 2$, definido como o efeito da dieta com Gordura Animal vs. Dieta com Gordura Vegetal, GA vs. GV.

O terceiro contrate ortogonal que vai ser designado como $\mathrm{C} 3$, definido como efeito das dietas com Gordura Animal + Gordura Vegetal vs. dieta Controle, (GA + GV) vs C. 
Será utilizado o nível de significância de 5\% para todos os testes realizados e tendência quando os valores estiverem entre 5 a $10 \%$.

Tabela 7 - Esquema de análise de variância para delineamento em Quadrado latino

\begin{tabular}{cc}
\hline Causas de variação & Graus de Liberdade \\
\hline Tratamentos & 3 \\
Contraste $1(\mathrm{C} 1)$ & $(1)$ \\
Contraste 2 (C2) & $(1)$ \\
Contraste 3 (C3) & $(1)$ \\
Períodos & 3 \\
\hline Animais & 6 \\
\hline Resíduo & 15 \\
\hline Total de Unidades & \\
Experimentais & \\
\hline
\end{tabular}




\section{RESULTADOS E DISCUSSÃo}

Os quatro animais apresentaram ganho de peso durante o período do experimento, sendo que o Vico obteve um ganho de $56 \mathrm{~kg}$, o Vivo de $40 \mathrm{~kg}$, o Virtual de $55 \mathrm{~kg}$ e o Veloz de $44 \mathrm{~kg}$.

Os resultados estão descritos nos dados que se seguem.

\subsection{ACEITABILIDADE}

Quanto à aceitabilidade, não foi observada diferença significativa entre as diferentes dietas com adição com gordura, de óleo mineral e com o controle, concordando com Holland (1996) que trabalhou com níveis de óleo de soja de 15\% de gordura adicionado a dieta é rapidamente aceita pelos eqüinos, com Geelen (2001) que também não observou variação entre a aceitabilidade de dieta controle com gordura fornecida para eqüinos. Do mesmo modo Snyder et al. (1981) trabalhando com gorduras para eqüinos não observou alteração na aceitabilidade dos animais para as dietas.

Segundo Potter, Weeb e Evans (1992) que ofereceram gordura animal entre outros tipos de gordura para eqüinos, observaram que a aceitabilidade dos animais quanto a dieta acrescida de gordura animal não variou se comparada com as outras gorduras utilizadas.

Mesmo o tratamento contendo óleo mineral não alterou a aceitabilidade, ingrediente de alta possibilidade de resistência à ingestão, possivelmente devido à quantidade utilizada nesse experimento, não sendo suficiente para promover alterações no comportamento alimentar dos potros.

E discordando desse experimento Bowman, Fontenot e Webb (1977) utilizaram 10 tipos de óleos e misturas diferentes de gordura adicionadas na dieta para verificar a aceitabilidade dos eqüinos, sendo observado a predileção pela dieta com adição de óleo de milho. 


\subsection{COEFICIENTE DE DIGESTIBILIDADE APARENTE}

Os resultados do coeficiente de digestibilidade aparente e suas probabilidades estão representados na tabela 8 .

Tabela 8 - Coeficientes de digestibilidade aparente da matéria seca (CDAMS), matéria orgânica (CDAMO), proteína bruta (CDAPB), extrato etéreo (CDAEE), fibra em detergente neutro (CDAFDN), fibra em detergente ácido (CDAFDA), seus respectivos valores de $\mathrm{P}$ e desvio padrão, para os tratamentos testados

\begin{tabular}{|c|c|c|c|c|c|c|c|c|}
\hline \multirow[b]{2}{*}{$\%$} & \multicolumn{4}{|c|}{ Tratamentos } & \multirow[b]{2}{*}{ D P } & \multicolumn{3}{|c|}{ Probabilidade } \\
\hline & Controle & $\begin{array}{c}\text { Óleo } \\
\text { vegetal }\end{array}$ & $\begin{array}{c}\text { Gordura } \\
\text { animal }\end{array}$ & $\begin{array}{c}\text { Óleo } \\
\text { Mineral }\end{array}$ & & C1 & $\mathrm{C} 2$ & C3 \\
\hline CDAMS & 62,5800 & 62,9425 & 64,6075 & 58,8975 & 2,99 & 0,0136 & 0,1398 & 0,2437 \\
\hline CDAMO & 64,4125 & 64,3275 & 66,1875 & 60,2900 & 3,02 & 0,0133 & 0,1683 & 0,4427 \\
\hline CDAPB & 67,3525 & 64,3500 & 66,5850 & 64,9450 & 2,5 & 0,2067 & 0,2369 & 0,2479 \\
\hline CDAEE & 77,7225 & 86,4675 & 90,2600 & 32,0200 & 24,48 & $<0,0001$ & 0,3566 & 0,0178 \\
\hline CDAFDA & 44,3075 & 43,7200 & 46,3600 & 42,7275 & 4,85 & 0,3024 & 0,1084 & 0,5680 \\
\hline CDAFDN & 50,0200 & 48,7075 & 51,5525 & 49,0025 & 3,44 & 0,5012 & 0,0924 & 0,9317 \\
\hline
\end{tabular}




\subsection{DIGESTIBILIDADE DA MATÉRIA SECA E MATÉRIA ORGÂNICA}

No contraste C2 onde foi comparado o efeito das dietas com adição de gordura animal e vegetal e o contraste 3 que comparou a adição dos dois tipos de gordura com a dieta controle, não foi observado resultado estatístico significativo, não alterando os valores de coeficiente de digestibilidade aparente da MS e MO, confirmando os dados citados por Todd et al. (1995) que observaram que não houve alteração na digestibilidade entre as dietas controle e com gordura em seu experimento, e, do mesmo modo Bush et al. (2001) utilizou em seu experimento o efeito da gordura dietética sobre a digestibilidade de nutriente, in vitro, no líquido cecal eqüino. Dois pôneis eram alimentados apenas com alfalfa ou com alfalfa mais óleo de milho (100 $\mathrm{g} / \mathrm{dL})$. Cinco substratos foram usados para determinar a digestibilidade in vitro de matéria seca, matéria orgânica. O suplemento energético não afetou, in vitro, a digestibilidade de matéria seca e da matéria orgânica.

Segue a figura 1 com o gráfico demonstrando os valores de coeficiente de digestibilidade aparente da MS e da MO da dietas oferecidas. 


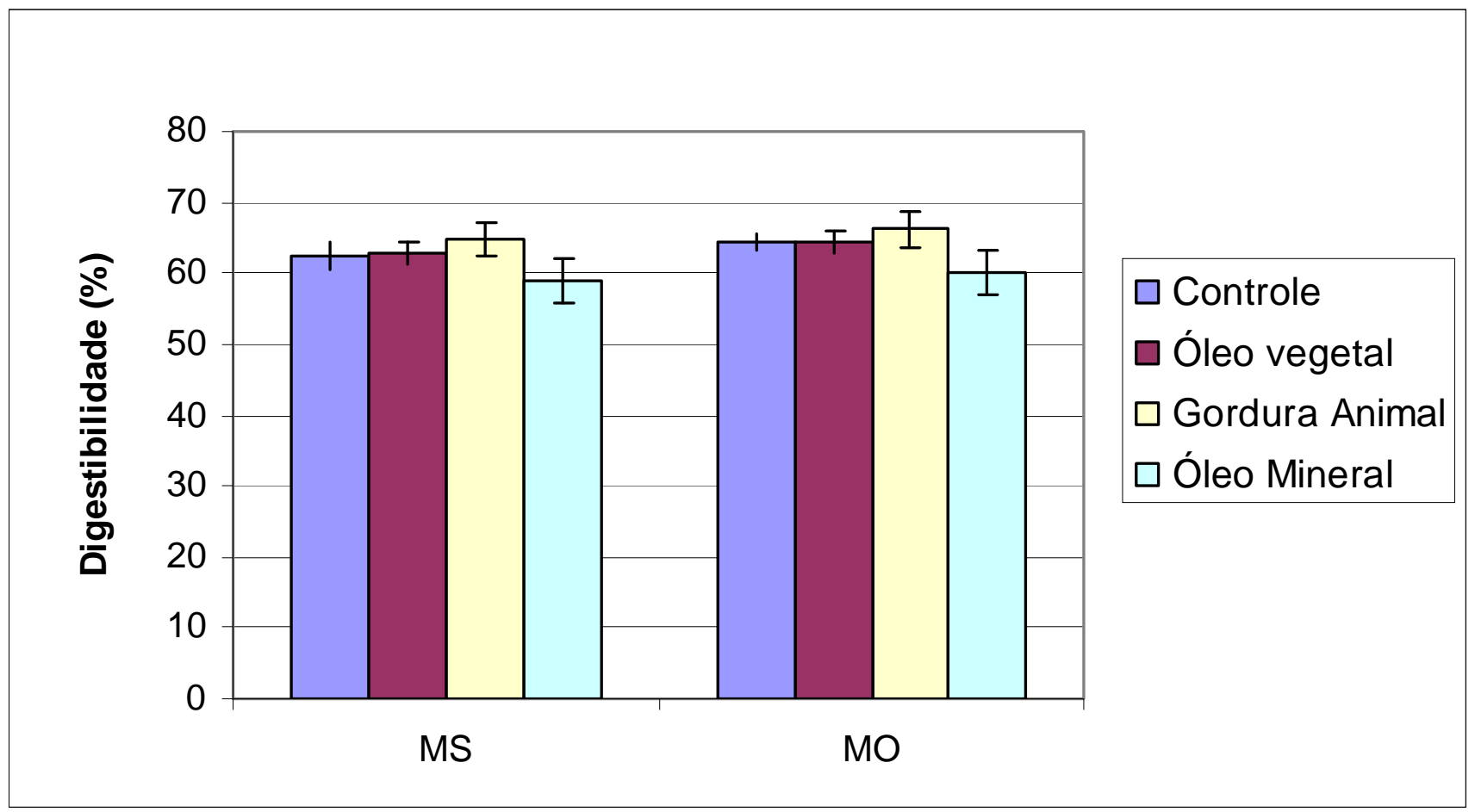

Figura 1 - Coeficiente de Digestibilidade aparente da Matéria Seca (CDAMS) e Matéria Orgânica (CDAMO) em \%, de todas as fontes mais o controle com o Desvio Padrão 
A dieta contendo óleo vegetal não afetou significativamente a digestibilidade da MS, confirmando os resultados do estudo de Kronfeld, Ferrante e GrandJean (2004), que constataram que óleos vegetais quando adicionados a outros alimentos não apresentam alteração da digestibilidade dos demais nutrientes, demonstrando valores assintomáticos de digestibilidade em 95\% dos testes utilizados. Concordando com esse experimento Julen et al. (1995) referem que não houve diferença na digestibilidade entre a dieta com gordura vegetal e com a dieta controle, sendo os valores de digestibilidade médios, respectivamente de 89,01 e 88,32 \%.

Resende JR et al. (2004) afirmam que o aumento da quantidade de óleo de milho não alterou a digestibilidade da MS sendo que seu trabalho foi efetuado com quatro tratamentos correspondentes a adição do óleo vegetal de $0,250,500$ e $750 \mathrm{ml}$, com os respectivos resultados de digestibilidade de Matéria Seca de 50,37, 49,58, 49,64 e 53,72\%. Confirmando os dados do experimento do Rammerstorfer, Potter e Cudd (1998) que referem que a adição de óleo na dieta de eqüinos não altera a digestibilidade de MS e MO.

Discordando desse experimento Kane, Baker e Bull (1979) descrevem que a inclusão de óleo de milho na dieta para eqüinos diminui a digestibilidade aparente da Matéria seca, no mesmo sentido Haaland et al. (1981) oferecendo diversos tipos de gorduras adicionado na dieta de bovinos observaram que na dieta com inclusão de sebo protegido diminui a digestibilidade aparente da MS.

Do mesmo modo McCann, Meacham e Fontenot (1987) citam em seu experimento, onde foi adicionado a dieta de eqüinos, óleo de milho, mistura de gordura vegetal e animal, e, cera não comestível, observaram que o óleo vegetal aumentou a digestibilidade aparente da MS e não ocorrendo variação na digestibilidade aparente da MS entre as outras duas dietas com os respectivos valores de digestibilidade aparente, 76,87 \%, 71,05 \%, 74,36 e 72,64 \%. Muitos estudos concluíram que a digestibilidade, dos óleos vegetais excede $90 \%$ e da gordura animal é ligeiramente menor (VALENTINE et al., 2001) discordando com os resultados encontrados nesse experimento.

No primeiro contraste foi observado diferença significativa entre a dieta controle e a dieta contendo óleo mineral no coeficiente de digestibilidade aparente da Matéria Seca e da Matéria Orgânica. Existem duas possibilidades sobre a interferência do óleo mineral com os nutrientes, a primeira é que o óleo mineral envolveu os nutrientes impossibilitando $o$ contato da bile $e$ das enzimas 
pancreáticas, impedindo a formação micelar (LEWIS, 2000), a segunda hipótese é que o óleo mineral formou uma película na parede intestinal, diminuindo a absorção dos nutrientes causando a menor digestibilidade da Matéria Seca e da Matéria Orgânica (CHOWDHURY, 2006).

Outra explicação seria que o óleo mineral poder alterar a taxa de passagem do alimento e assim, levando a baixa digestão da Matéria Seca e da Matéria Orgânica, concordando com Jansen (2000) citados por Resende (2002), que declararam que a utilização de óleo afeta a digestibilidade dos nutrientes da dieta, por alterar a taxa de passagem do alimento e provocar inibição no desenvolvimento da microflora do intestino grosso. 


\subsection{DIGESTIBILIDADE DA PROTEINA BRUTA}

Os coeficientes de digestibilidade aparente da Proteína Bruta (PB) para os quatro tratamentos se mantiveram nivelados nos três contrastes utilizados por esse experimento, não sendo estatisticamente significativo.

Discordando desse experimento Beynen e Hallebeek (2002) referem que dietas com alto teor de gorduras possuem um efeito inibitório na digestibilidade aparente proteína, sendo o aumento da concentração lipídio dietético em $10 \mathrm{~g} / \mathrm{kg}$ na matéria seca, promove uma diminuição na digestibilidade uma diminuição na digestibilidade da proteína de 0,7.

No experimento feito por Jansen (2000), não encontrou diferença estatística significativa na digestibilidade de PB. $O$ autor cita duas teorias a primeira é que a ingestão de dieta contendo uma maior quantidade de gordura pode causar um menor crescimento das bactérias do intestino grosso que diminuiria a quantidade da proteína microbiana fecal, criando assim uma menor digestibilidade aparente da proteína bruta, concomitantemente, por outro lado um maior consumo de gordura na dieta deprime a digestão aparente do intestino delgado devido ao aumento do fluxo do nitrogênio endógeno, também reduzindo a digestibilidade do estrato nitrogenado.

Segue figura 2 com o gráfico demonstrando os valores de coeficiente de digestibilidade aparente da PB das dietas oferecidas. 


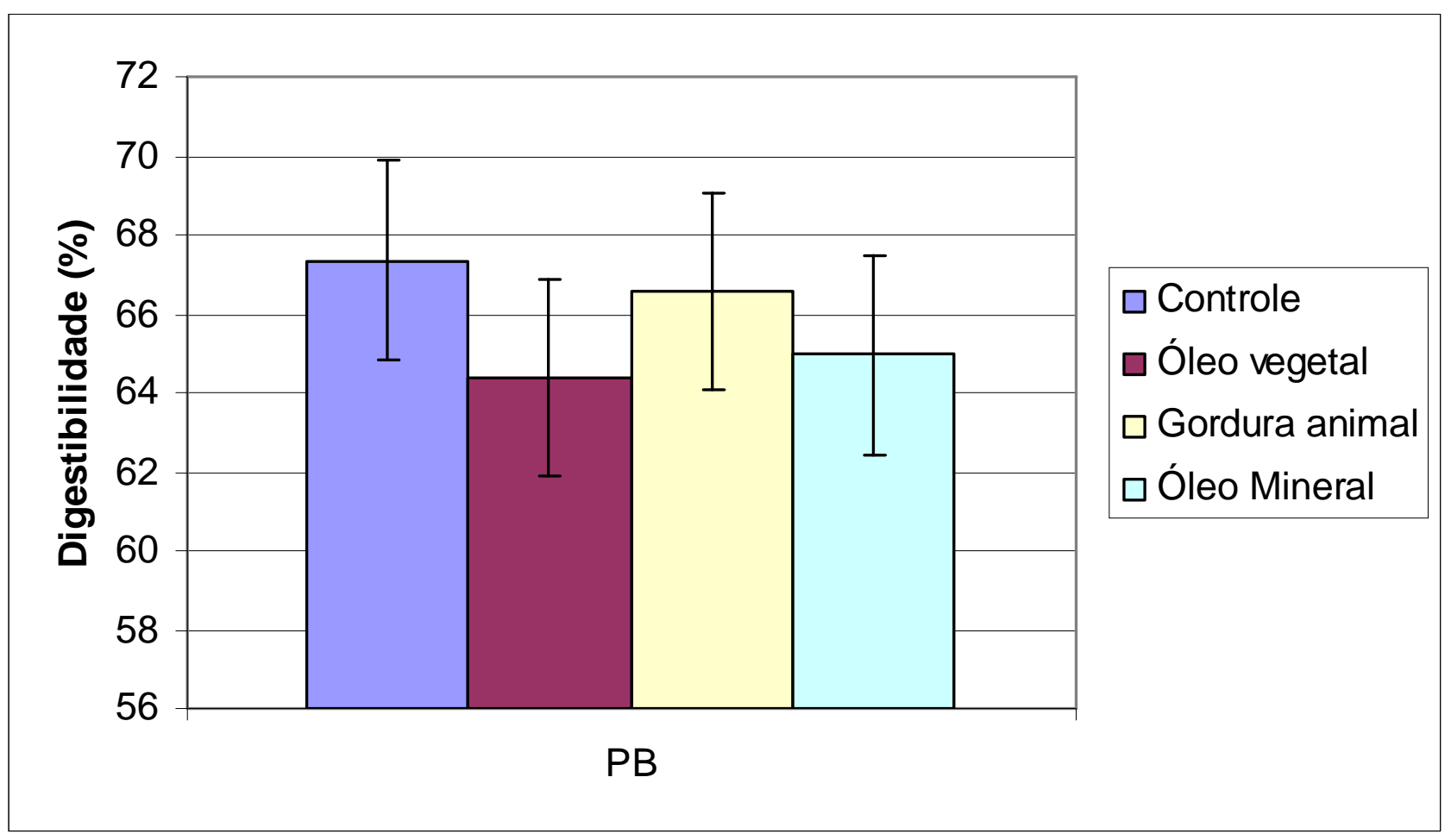

Figura 2 - Coeficiente de digestibilidade aparente da Proteína Bruta (CDAPB) em \%, de todas as fontes mais o controle com o Desvio Padrão 
Resende JR et al. (2004) realizaram um trabalho fornecendo níveis de óleo de milho, com uma dieta controle, dietas sendo adicionado 250, 500 e $750 \mathrm{ml}$ de óleo, não observou alteração em seus resultados de digestibilidade de Proteína Bruta, $59,26 \%$ para a dieta controle, $61,25 \%$ para dieta com $250 \mathrm{ml}$ de óleo, 58,07\% para dieta contendo $500 \mathrm{ml}$ de óleo e $62,61 \%$ para dieta contendo $750 \mathrm{ml}$ de óleo, não obtendo assim valores estatísticos significativos, conferindo com os resultados desse trabalho.

Concordando com esse experimento McCann, Meacham e Fontenot (1987) referem que em seu trabalho que não observaram efeito na digestibilidade da Proteína Bruta aparente, utilizando dieta controle, dieta com $15 \%$ de suplementação com óleo de milho, $15 \%$ de mistura de gordura animal e vegetal, e $15 \%$ de cera de vela, com os seguintes valores respectivos de digestibilidade aparente de proteína Bruta $77,97 \% ; 78,59 \%$ e 75,08 \%.

Do mesmo modo, o experimento efetuado por Bowman, Fontenot e Webb (1977) ofereceram dietas com adição de gordura para eqüinos também não observaram variação no coeficiente de digestibilidade aparente de Proteína Bruta, o mesmo foi observado por Rich, Fonetnot e Meacham (1981) que adicionaram gordura animal, vegetal e a mistura das duas gorduras em seu experimento, não obtiveram diferença estatística no coeficiente de digestibilidade aparente desse nutriente. Seguindo o mesmo conceito Webb, Potter e Evans (1987) forneceram dieta com gordura vegetal e dieta controle para eqüinos não observaram valores significativos para o coeficiente de digestibilidade de PB.

Concordando com os resultados desse experimento Bush et al. (2001) comparando dieta controle com dieta com gordura não observaram alteração no coeficiente de digestibilidade aparente de PB, Cunha (1991) e Carvalho (1992) não observaram variação na digestibilidade de PB em dietas controle e com adição de gordura. 


\subsection{DIGESTIBILIDADE DO EXTRATO ETÉREO}

Na digestibilidade aparente do EE o contraste $\mathrm{C}$ 1, onde confrontamos a dieta controle com a dieta com óleo mineral foi observado valor significativo estatisticamente $(P<0,0001)$, mas de fato o óleo mineral não afetou a digestibilidade aparente do EE da dieta, fato demonstrado através da quantidade em gramas de EE digerido das dietas dos tratamentos controle e com óleo mineral, respectivamente, $141,9 \mathrm{~g}$ e $154,5 \mathrm{~g}$, valores semelhantes entre si, indicando que 0 óleo mineral não foi absorvido, e apenas a gordura da dieta foi absorvida, concordando com Andrade et al. (2002) e Spinosa (1999), que trabalhando com eqüinos não verificaram diferenças na digestibilidade de dietas com adição de óleo mineral, e, concordando com ChowdHury (2006) que relata em seu artigo que óleo mineral não é absorvido por humanos.

Segue a figura 3 com o gráfico demonstrando os valores de coeficiente de digestibilidade aparente do EE das dietas oferecidas. 


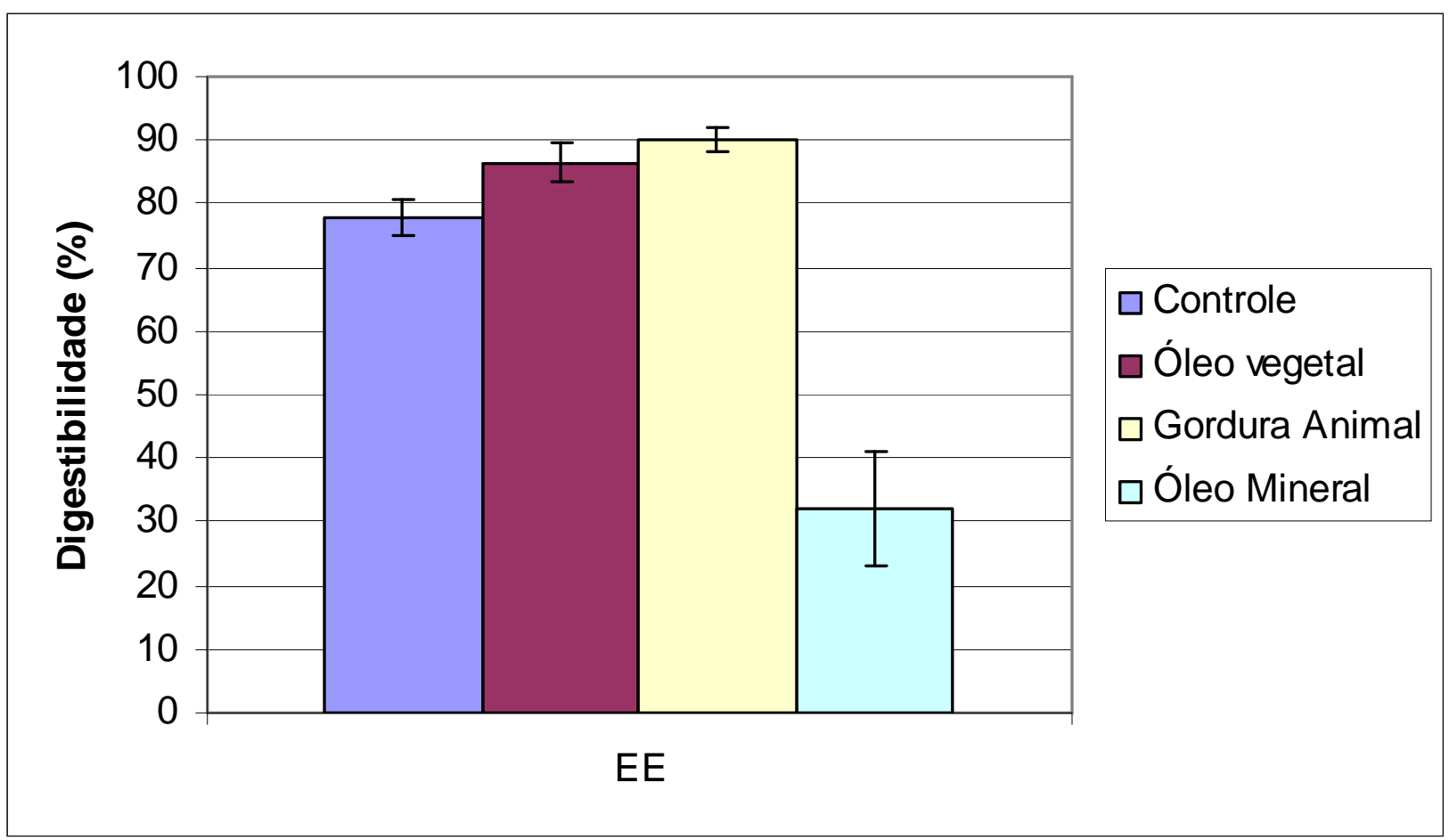

Figura 3 - Coeficiente de digestibilidade aparente do Estrato Etéreo (CDAEE) em \%, de todas as fontes mais o controle com o Desvio Padrão 
Não foi verificada diferença do coeficiente de digestibilidade aparente do EE no contraste $\mathrm{C} 2$, que observa o efeito entre a dieta contendo gordura vegetal e a dieta contendo gordura animal, do mesmo modo que Meyers et al. (1989), que compararam dietas sem adição de gordura com dietas com adição de gordura animal, não observando diferença estatística significativa sobre o coeficiente de digestibilidade aparente do EE entre as dietas de seu experimento.

Por outro lado, McCann, Meacham e Fontenot (1987) que em seu experimento adicionaram vários tipos de gorduras na dieta para eqüinos observando o aumento da digestibilidade aparente do EE com dieta adicionada com gordura vegetal, afirmam que esse efeito pode ser parcialmente atribuído a suplementação com gordura, pois esta provoca a diluição da gordura fecal endógena elevando a digestibilidade aparente. Deste modo, a magnitude da diferença entre a digestibilidade basal e com suplementação com gordura sugere que as gorduras foram mais digeríveis do que os grãos, concordando com os resultados de outros trabalhos (KANE; BAKER, 1977; KANE; BAKER; BULL, 1979; MCCANN; MEACHAM; FONTENOT 1987; SCOTT, 1996; HUGHES et al., 1995; JULEN et al., 1995).

Foi observado valor significativo no contraste C3, onde foi identificado maior digestibilidade aparente do EE das dietas, com gordura animal e gordura vegetal em relação ao controle, não concordando com os resultados apresentados por Kronfeld, Rodiek e Stull (2004) que forneceram dietas com gordura vegetal e dieta controle para eqüinos e verificaram que a adição de gordura vegetal não alterou estatisticamente os resultados do coeficiente de digestibilidade aparente do Estrato Etéreo em relação ao controle. Do mesmo modo Webb, Potter e Evans (1987) adicionando óleo vegetal na dieta de eqüinos não observaram resultados estatísticos significativos entre o controle sem adição de óleo e a dieta com adição de óleo vegetal.

Concordando com esses experimentos Kronfeld, Rodiek e Stull (2004) relatam que o aumento da digestibilidade aparente do EE com adição de gordura animal foi observado em relação ao controle. Esse aumento pode ser atribuído a diluição dos componentes indigeríveis do EE nos grãos e especificamente nas forragens pela alta digestibilidade dos triglicérides.

Segundo Julen et al. (1995) o aumento de digestibilidade do Estrato Etéreo quando a dieta possui gordura pode ser explicado por uma série mecanismos, por 
exemplo, a gordura na dieta pode ser de mais fácil digestão do que o EE nos ingredientes presentes na dieta controle; o maior consumo de óleo e de gordura aumenta a produção de bile e de lípase, conseqüentemente aumentando a digestibilidade do EE.

A absorção intestinal de fontes saturadas torna-se maior quando há presença concomitante de ácidos graxos insaturados, especialmente o ácido oléico, o que denota um efeito sinérgico na digestibilidade dos ácidos graxos saturados (NRC, 2007), provavelmente em razão de maior emulsificação no intestino (CHALUPA et al., 2002) pelo fato de o sebo suíno caracterizar-se por apresentar em sua composição $43 \%$ de ácido oléico, $23 \%$ de ácido palmítico e $13 \%$ de esteárico, ácidos graxos saturados (TURATTI; GOMES; ARTHIE, 2002). 


\subsection{DIGESTIBILIDADE DO FDA E DO FDN}

Não foi observada variação na digestibilidade aparente nos coeficientes de digestibilidade aparente do FDA e do FDN nos 3 contrastes ortogonais utilizados nesse experimento, apenas uma tendência no coeficiente de digestibilidade aparente no contraste $\mathrm{C} 2$ em relação a digestibilidade do FDN.

Jansen (2000) relata que não houve queda significativa na digestibilidade de Fibra Bruta em dietas com óleo de soja. Segundo Bush et al. (2001) não houve diferença na digestibilidade da FDN nos pôneis que se alimentaram de gordura animal, óleo de soja ou a mistura das duas gorduras. Concordando com os trabalhos de Resende (2002) em que a adição crescente de óleo não afetou a digestibilidade aparente da fibra de detergente neutro e fibra de detergente ácido.

Segue a figura 4 com o gráfico que demonstram os valores de coeficiente de digestibilidade aparente do FDN e FDA das dietas oferecidas. 


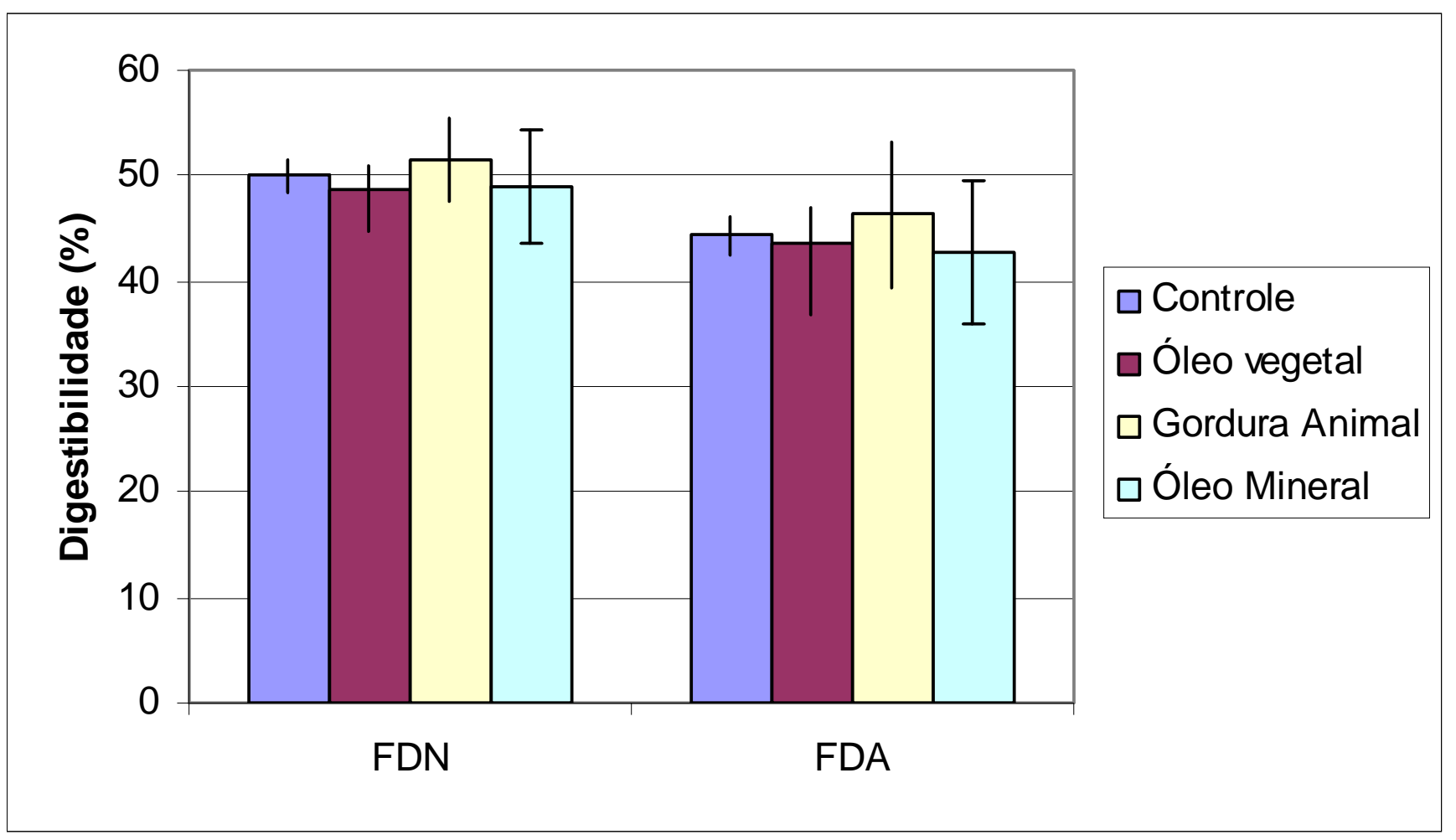

Figura 4 - Coeficiente de digestibilidade aparente da Fibra Detergente Neutra (CDAFDN) e Fibra Detergente Ácida (CDAFDA) em \%, de todas as fontes mais o Controle com o Desvio Padrão 
Os resultados da digestibilidade aparente de FDN e FDA apresentados na literatura muitas vezes discordam entre si, segundo Beynen e Hallebeek (2002) dietas com alto teor de gorduras possuem um efeito inibitório na digestibilidade aparente de fibra bruta, proteína e carboidratos não-estruturais, sendo o aumento da concentração lipídio dietético em $10 \mathrm{~g} / \mathrm{kg}$ na matéria seca, promove uma diminuição na digestibilidade da fibra bruta de $0,9 \%$, uma diminuição na digestibilidade da proteína de 0,7 \% e um aumento na digestibilidade do extrato etéreo de 0,9\%.

Os diferentes resultados provavelmente estão relacionados com as diferentes quantidades de gordura utilizadas em vários estudos que influi no consumo dos ingredientes das dietas fornecidas aos animais, inclusive os teores de fibra bruta (MORGADO; GALZERANO, 2006).

Uma mudança no consumo da fibra pode afetar a porcentagem da digestibilidade aparente da fibra assim como a taxa de passagem do alimento que pode ser alterada, e a microflora será exposta a uma mudança na quantidade de substratos fermentáveis (BEYNEM; HALLEBEEK, 2002). Jansen (2000) citado por Resende (2002), declararou que a utilização de óleo pode afetar a digestibilidade dos nutrientes da dieta, por alterar a taxa de passagem do alimento e provocar inibição no desenvolvimento da microflora do intestino grosso, levando a baixa digestão de FDN e FDA.

Nesse experimento, foi possível observar uma tendência em relação ao segundo contraste em que é apresentado o efeito entre a gordura animal e vegetal na digestibilidade do FDN $(P=0,0924)$, mas não sendo estatisticamente significativo.

Segundo Julen et al. (1995), o aumento relativo da digestibilidade aparente do FDN pela gordura animal pode ser devido à remoção dos efeitos supressivos da fermentação do amido na digestão de fibra no intestino grosso por substituição da gordura por carboidratos cordando com esse experimento.

De acordo com Mandarino (1995), os ácidos graxos saturados são constituintes da banha de porco e sebo bovino; óleos com altos teores de ácidos graxos monoinsaturados, e os óleos com altos teores de ácidos graxos poliinsaturados, principalmente linoléico são constituintes do óleo de soja, observando esse fato Julen et al. (1995) referem que os efeitos inibitórios dos ácidos graxos na fermentação cecal dependem do tipo e da concentração desses ácidos, que em estudos efetuados com culturas in vitro de microflora do intestino grosso de 
eqüinos que tiveram contato com ácidos graxos saturados de cadeia curta de até seis carbonos não demonstrou muita inibição na fermentação, mas com ácidos graxos saturados de cadeia de carbono maior, obteve maior efeito sobre a fermentação, mas os ácidos graxos poliinsaturados como os ácidos linolenato e linoleato inibiram o crescimento bacteriano das bactérias gram - em maior grau. Do mesmo modo Chalupa et al. (2002) referem em seu experimento com adição de gorduras para bovinos, que observou melhora da digestibilidade dos nutrientes em dietas com adição de gordura animal e vegetal concomitantemente, observando que ocorre um sinergismo nos dois tipos de gordura, melhorando a digestibilidade dos nutrientes, sendo demonstrado nesse experimento com a adição da gordura animal mais o concentrado que possui óleo de soja extrusado causando assim um possível sinergismo. 


\subsection{VALORES BIOQUÍMICOS PLASMÁTICOS}

Os resultados obtidos da dosagem plasmática de Colesterol, triglicérides, VLDL-C, HDL-C, LDL-C, estão demonstrados na tabela 9 e figuras 5 e 6.

Tabela 9 - Resultados bioquímicos plasmáticos das três fontes mais o controle de Colesterol, HDL-C, LDL-C, VLDL-C e triglicérides

\begin{tabular}{|c|c|c|c|c|c|c|c|c|}
\hline \multirow[b]{2}{*}{$\mathrm{mg} / \mathrm{dL}$} & \multicolumn{4}{|c|}{ Tratamentos } & \multirow[b]{2}{*}{ D P } & \multicolumn{3}{|c|}{ Probabilidade } \\
\hline & Controle & $\begin{array}{c}\text { Óleo } \\
\text { Vegetal }\end{array}$ & $\begin{array}{c}\text { Gordura } \\
\text { Animal }\end{array}$ & $\begin{array}{c}\text { Óleo } \\
\text { Mineral }\end{array}$ & & C1 & C2 & C3 \\
\hline COL & 98,75 & 89,25 & 99,75 & 94,75 & 11,5 & 0,5073 & 0,1138 & 0,4204 \\
\hline HDL-C & 76,00 & 73,25 & 74,75 & 68,75 & 9,53 & 0,0229 & 0,5529 & 0,3707 \\
\hline LDL-C & 20,75 & 13,50 & 22,45 & 22,00 & 7,46 & 0,8191 & 0,1380 & 0,5628 \\
\hline VLDL-C & 2,00 & 2,50 & 2,55 & 4,00 & 3,55 & 0,2299 & 0,9742 & 0,6972 \\
\hline TRIG & 10,25 & 17,50 & 15,50 & 22,75 & 14,6 & 0,4804 & 0,7365 & 0,4240 \\
\hline
\end{tabular}




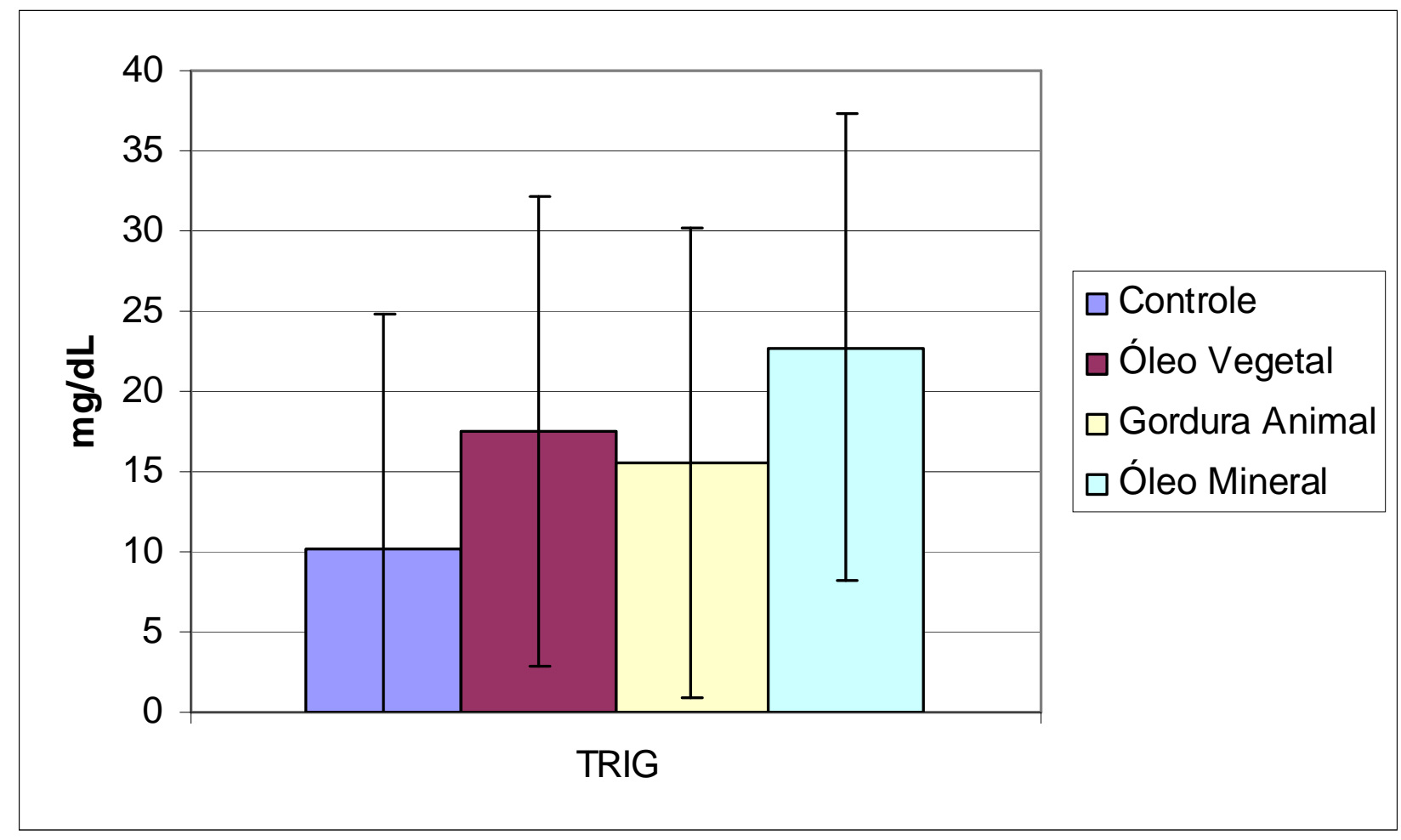

Figura 5 - Concentrações plasmáticas de Triglicérides dos animais que consumiram as três fontes mais o controle com Desvio Padrão 


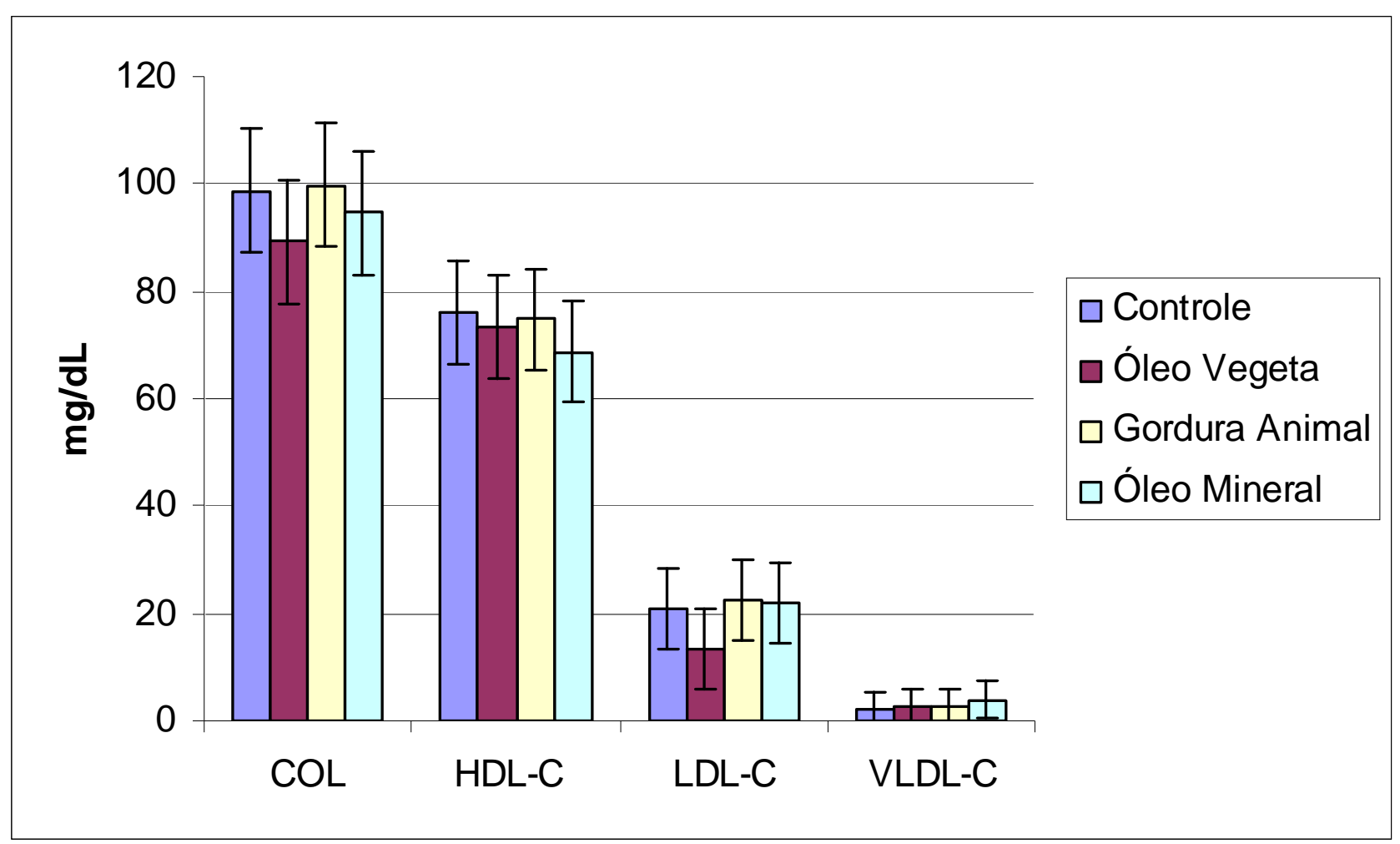

Figura 6 - Concentrações plasmáticas de Colesterol, HDL-C, LDL-C e VLDL-C dos animais que consumiram as três fontes mais o controle com o Desvio Padrão 
Os valores de triglicérides foram de 10,25 $\mathrm{mg} / \mathrm{dL}$ para a dieta controle, 17,50 $\mathrm{mg} / \mathrm{dL}$ para o óleo vegetal, $15,50 \mathrm{mg} / \mathrm{dL}$ para a gordura animal; e 22,75 mg/dL para o óleo mineral, não obtendo valor significativo entre os contrastes ortogonais utilizados nesse experimento, concordando com Marchello et al. (2000) que os triglicérides também não variaram entre a dieta controle e a dieta com gordura vegetal, do mesmo modo Geelen (2001) reportou em seu trabalho feito com eqüinos alimentados com óleo de soja em quatro diferentes concentrações, os valores de triglicérides não apresentaram valor estatístico significativo, Hallebeek (2002) relata que não obteve alteração dos resultados na mensuração de triglicérides entre dietas com adição de óleo de palma e de soja.

Os valores de triglicérides não foram significativos, mas apresentaram um aumento na concentração nas três dietas com adição de gordura e óleo, estudas nesse experimento, sendo explicado por Siciliano e Wood (1993), utilizando dieta controle e dieta contendo óleo de soja, observaram que as concentrações plasmáticas de triglicérides e colesterol aumentaram no período experimental. Este aumento plasmático contribuiu para um efeito linear nos lipídeos totais. $\mathrm{O}$ aumento na concentração plasmática de lipídeos totais em ambos os grupos deve refletir a síntese em excesso de metabólicos no armazenamento de triglicérides. Ambos os grupos de cavalos assumiram um balanço energético positivo porque ganharam peso ao longo do experimento, concordando com esse experimento, pois os animais obtiveram um ganho de peso durante o experimento.

Quanto aos resultados plasmáticos de colesterol, os níveis não apresentaram diferença significativa em suas concentrações nos três contrastes ortogonais utilizados nesse experimento. Os valores de colesterol foram de $98,75 \mathrm{mg} / \mathrm{dL}$ para a dieta controle, $89,25 \mathrm{mg} / \mathrm{dL}$ para óleo vegetal, $99,75 \mathrm{mg} / \mathrm{dL}$ para gordura animal e $94,75 \mathrm{mg} / \mathrm{dL}$ para óleo mineral; não sendo estatisticamente significativo nesse experimento entre os três contrastes ortogonais. Concordando com Fernandez e McNamara (1994) que em seu experimento com suínos alimentados com semente de palma, óleo de palma, banha de porco, gordura bovina, óleo de oliva e óleo de milho com os seguintes resultados de colesterol, respectivos, $6,2 \mathrm{umol} / \mathrm{g} ; 4,4 \mathrm{umol} / \mathrm{g}$; $6,1 \mathrm{umol} / \mathrm{g} ; 5,9 \mathrm{umol} / \mathrm{g} ; 5,4 \mathrm{umol} / \mathrm{g}$ e $5,9 \mathrm{umol} / \mathrm{g}(\mathrm{P}<0,01)$ não obtendo valor estatístico significativo. 
No trabalho de Marchello et al. (2000) não apresentou valores significativos estatísticos de colesterol, entre os animais que consumiram dieta controle e com gordura, Hamblenton (1980) que fez com diferentes níveis de óleo de soja não obtendo valores significativos estatisticamente e por Etherton e Kensinger (1984) trabalhando com ratos fornecendo óleo de alçafroa, óleo de milho, óleo de oliva e óleo de palma apresentou os seguintes valores de colesterol 20,4 mg/dL; 17,4 mg/dL ; 18,2 mg/dL e 14,2 g/ml respectivamente $(P<0,05)$ não apresentando nenhuma alteração estatística significante se igualando a esse experimento. Segundo Luhman, Faidley e Beitz (1992) que observaram valores significativos para dietas com adição de gordura em suínos. No experimento de Siciliano e Wood (1993), utilizando dieta controle e dieta contendo óleo de soja, observaram que a concentração plasmática de colesterol aumentou no período experimental não concordando com o resultado desse experimento.

O colesterol apresentou um aumento na dieta com adição de gordura animal e uma queda com a dieta com gordura vegetal, mas não sendo estatisticamente significativo, podendo ser explicado por Hallebeek (2002) quando ocorre a troca de dietas ricas em ácidos graxos saturados, por ácidos graxos insaturados ocorre uma diminuição na quantidade de colesterol, sendo observado por Packard (1999) que a queda do colesterol pode ocorrer pela saturação dos ácidos graxos da dieta, os mecanismos ainda não são esclarecidos, mas pode ocorrer pela interferência com o receptor mediador do LDL-C. Segundo Garg, Thomson e Clandinin (1989) explicam que a diminuição de colesterol em humanos ocorre pela inibição da síntese endógena do colesterol por inibição da HMG-COa redutase, responsável pela síntese do colesterol, aumentando a taxa de esterificação do colesterol. Grundy (1996) relata que os ácidos graxos da dieta com gordura animal são quase em sua totalidade de ácidos graxos saturados e a dieta com gordura vegetal de ácidos graxos insaturados,

Nos resultados das frações de colesterol, os níveis de LDL-C, a dieta com gordura animal apresentou um maior volume, seguido pela dieta com óleo mineral, depois pela dieta controle e depois com a dieta com gordura vegetal, mas não sendo estatisticamente significativo, nos três contrastes ortogonais usados nesse experimento, fato observado por Pimenta et al. (2001) que observou um aumento de LDL com o aumento de gordura de coco na dieta em suínos, mas não sendo estatisticamente significativo, Hayes (2001), que observou que dietas com ácidos 
graxos insaturados diminuem o índice de LDL-C e com dieta com ácidos graxos saturados aumentam, representado aqui com a dieta com gordura animal que aumentou os valores de LDL-C e na dieta com gordura vegetal que diminuiu.

No experimento de Marchello et al. (2000) observaram que com a adição de gordura na dieta aumenta o valor de LDL-C, devido a uma maior produção de bile, excretada para solubilizar a gordura da dieta, conseqüentemente uma maior quantidade de colesterol endógeno vai ser absorvido, sendo evidenciado pelo aumento de LDL-C. No experimento de Siciliano e Wood (1993), foi observado que os valores de LDL-C não obtiveram valores significativos estatisticamente entre os tratamentos com diferentes fontes de gordura para eqüinos, do mesmo modo Etherton e Kensinger (1984) utilizando ratos, não foi observado valores significativos na dosagem de LDL-C entre os tratamentos, concordando com esse experimento.

Os valores de VLDL-C não foram observados resultados significativos nos três contrastes ortogonais aqui utilizados, com os valores muito próximos entre os três tratamentos mais o controle, concordando com o trabalho de Fernadez e McNamara (1994) onde foi fornecida semente de palma, óleo de palma, banha de porco, gordura bovina, óleo de oliva e óleo de milho para suínos, no experimento de Marchello et al. (2000) não observou variação nos resultados de VLDL-C entre o tratamento com óleo e o controle após quatro semanas de tratamento, em seu experimento, os resultados de VLDL-C e colesterol no intervalo de 3 horas após a alimentação, não apresentaram variação aparente entre os resultados.

No valor de HDL-C foi observado valor significativo no primeiro contraste onde foi observado o efeito entre o óleo mineral sobre o controle $(P=0,0229)$, diminuindo 0 nível de HDL-C com a inclusão de óleo mineral, não sendo observado valores significativos no segundo e terceiro contraste utilizado nesse experimento, discordando desse experimento os trabalhos de McCann, Meacham e Fontenot (1987) e Hambleton et al. (1990) referem que a adição de gorduras na dieta não alteram os níveis de HDL-C. Concordando com esse experimento Marchello et al. (2000) relata que com o aumento de gordura na dieta aumenta a produção de bile, que conseqüentemente aumenta a absorção de colesterol endógeno, aumentando assim os níveis de HDL, fato observado também por Geelen (2001) que observou relação entre o aumento dos níveis de óleo de soja, com o aumento do colesterol total e do HDL-C, justificando que esse aumento foi devido ao aumento de gordura da dieta conseqüentemente aumentando a atividade da lipoproteína lípase (LPL). 


\section{CONCLUSÃO}

Nas condições em que esse experimento foi desenvolvido é possível concluir que para eqüinos:

A adição das gorduras vegetal e animal e do óleo mineral não interferiram na aceitabilidade da dieta.

A adição de gordura animal na dieta não diferiu em relação à gordura vegetal adicionada a dieta na digestibilidade dos nutrientes e nos valores plasmáticos de gordura.

A adição de óleo mineral diminuiu a digestibilidade da $\mathrm{MS}, \mathrm{MO}$ em relação ao controle, não influenciando na digestibilidade aparente dos outros nutrientes.

A adição de gordura animal e de gordura vegetal a dieta melhorou a digestibilidade aparente do $\mathrm{EE}$ em relação ao controle, não alterando a digestibilidade dos outros nutrientes e não alterou os valores plasmáticos.

A adição de óleo mineral aumentou o valor plasmático de $\mathrm{HDL}$ em relação ao controle, não alterando os valores do Colesterol, Triglicérides, LDL e VLDL.

A adição de gordura vegetal e animal não provocaram alteração nos valores plasmáticos de gordura. 


\section{REFERÊNCIAS}

ANDRADE, S. F.; CAMARGO, P. L.; VIANNA, L. C.; BORNBUSCH, P. T. Terapêutica do Sistema Digestivo. In: ANDRADE, S. F. Manual de Terapêutica Veterinária. 2. ed. São Paulo: Roca, 2002. p. 230.

ALLAN, F. J.; THOMPSON, K. G.; JAMES, K. A. C.; MANKTELOW, B. W.; KOOLAARD, J. P.; JOHNSON, R. N.; McNUTT, P. V. Serum lipoprotein cholesterol and triglyceride concentrations in pigs fed diets containing fish oil, milkfat, olive oil and coconut oil. Nutrition Research, Tarrytown, v. 21, n. 5, p. 785-795, 2001.

ARGENZIO, R. A. Digestão e absorção dos carboidratos, gorduras e proteínas. In: SWENSON, M. J. (Ed.). Dukes fisiologia dos animais domésticos. 11. ed. Rio de Janeiro: Guanabara Koogan, 1996. p. 331-351.

ASSOCIATION ON OFFICIAL ANALYTICAL CHEMISTS - AOAC. Official methods of analysis, $14^{\text {th }}$ ed. Arlington, VA.: Association of Official Analytical Chemists 1984. $1141 \mathrm{p}$.

BEYNEN, A. C.; HALLEBEEK, J. M. High-fat diets for horses. In: EUROPEAN EQUINE NUTRITION \& HEALTH CONGRESS, 1., 2002, Holanda. Proceedings.... 2002. p. 35.

BLIKSLAGER, A. T. Principles of Treatment for Impaction - Laxatives, Fluid Therapy and Analgesia. In: AMERICAN ASSOCIATION OF EQUINE PRACTITIONERS AAEP -FOCUS MEETING, 2005, Québec, QC, Canada, 2007. Disponível em: < www.aaep.org>. Acesso em: set de 2007.

BOWMAN, V. A.; FONTENOT, J. P.; WEBB JR., K. E. Digestion of fat by equine. In: EQUINE NUTRITION PHYSIOLOGY SYMPOSIUM, 5., 1977, Missouri.

Proceedings...., 1977. p. 40.

BRUSS, M. L. Lipids and ketones. In: KANEKO, J. J. (Ed.). Clinical biochemistry of domestic animals. New York: Academic Press, 1980. p. 83-905.

BUSH, J. A.; FREEMAN, D. E.; KLINE, K. H.; MERCHEN, N. R.; FAHEY JR., G. C. Dietary fat supplementation effects on in vitro nutrient disappearance and in vivo nutrient intake and total tract digestibility by horses. Journal of Animal Science, v. 79, n. 1, p. 232-239, 2001. 
BYRD, B. M. Alkanes as Internal and External Markers in horses and the digestibility of a high fat cereal by-product. Dissertação (Mestrado) Virginia, Polytechnic Institute and State University, 2003, p. $40-51$.

CARVALHO , M. A. G. Digestibilidade aparente em eqüinos submetidos a três condutas de arraçoamento. 1992. 34 f. Dissertação (Mestrado em Produção Animal) - Escola de Veterinária da UFMG, Belo Horizonte, 1992.

CHALUPA, W.; VECCHIARELLI, B.; ELSER, A. E.; KRONFELD, D. S.; SKLAN, D.; PALMQUIST, D.L. Ruminal fermentation in vivo as influenced by long-chain fatty acids. Journal Dairy Science, v. 3, n. 69, p. 1293 - 1301, 1986.

CHOWDHURY, S. Exploring thes cience of laxatives: mechaninsms and modes of action. Nurse Prescribing, v. 4, n. 3, p. $107-112,2006$.

CORREA, A. A .D.; CORREA, J. H. R. Bioquímica animal. 2. ed. Lisboa: Fundação Calouste Guibenkian, 1985. 1249 p.

CORREA, M. P. Dicionário das plantas úteis do Brasil e as exóticas cultivadas. Rio de janeiro: Imprensa Nacional, 1984. v. 1, p. 35-40.

CUNHA, T. J. Horse feeding and nutrition. 2. ed. San Diego: Academic, 1991. 445p.

ETHERTON, T. D.; KENSINGER, R. S. Endocrine regulation of fetal and postnatal meat animal growth. Journal Animal Science, v. 59, p. 511, 1984.

FERNANDEZ, M. L.; McNAMARA, D. J. Dietary fat saturation and chain length modulate guinea pig hepatic cholesterol metabolism. American Institute of Nutrition, v. 38, n. 11, p. 331-339, 1994.

FERRANTE, P. L.; KRONFELD D. S. ROBINSON, N. E. 3 ed. Current therapy equine medicine. Phyladelphia: SAMDERS, W.B., 1992. p. 809-813.

FERREIRA, C. P.; JARROUGE, M. G.; DOMINGOS, M. D.; TUNDISI, M.; MARTIN, N. F. Bioquímica Básica. 2. ed. Falta local: Editora ampliada, 1998. p. 81 - 114. 
FILHO, N. R. A. Análise de óleos e gorduras vegetais utilizando métodos cromatográficos de alta resolução e métodos computacionais. 1995. $34 \mathrm{f}$. Tese (Doutorado em Química) - Instituto de Química de São Carlos, Universidade de São Paulo, São Carlos, 1995.

GARG, M. L.; THOMSON, A. B. R.; CLANDININ, M. T. Effect of dietary fish oil on tissue lipid metabolism. In: CHANDRA, R. K. (Ed.). Health effects of fish and fish oils. St. John's: ARTS biomedical publishers and distributors limited, 1989. p. 53-79.

GEELEN, S. N. J. Dietary fat supplementation and equine plasma lipid metabolism. 2001. 114 f. Tese (Doutorado em Nutrição Animal) - Universiteit Utrecht, Ultrecht, 2001.

GRUNDY, S. M. Dietary fat. In: ZIEGLER, E. E.; FILER JR., L. J. (Ed.). Present knowlegde in nutrition. 7. ed. Washington: ILSI, 1996. p. 44-57.

HAALAND, G. L.; MATSUSHIMA, J. K.; JHONSON, D. E; WARD, G. M. Nutritive value of protected tallow product fed with hay to feed cattle as assessed by respiration calorimetric. Journal of Animal Science, v. 52, n. 2, p. 391, 1981.

HALLEBEEK, J. M. Dietary fats and lipid metabolism in relation to equine health, performance and disease. In: Dietary control of equine plasma triacylglycerols. 2002. 140 f. Dissertação (Doutorado em Nutrição Animal) Universiteit Utrecht, Utrecht, 2002. p. 14-34.

HAMBLETON, P. L.; SLADER, L. D.; HAMAR, D. W.; KIENHOLZ, E. W.; LEWIS, L. $D$. Dietary fat and exercise conditioning effect on metabolic parameters in the horse. Journal of Animal Science, v. 51, n. 6, p. 1330-1339, 1990.

HAYES, K. C. The omega- 6 versus omega- 3 fatty acid modulation of lipoprotein metabolism. American Chemical Society. n. 4, p. $37-51,2001$.

HINTZ, H. F.; HOGUE, D. E.; WALKER, E. F. Apparent digestion in various segments of the digestive tracts of ponies, fed diets with varying roughage ration. Journal Animal Science, v. 32, n. 2, p. 245-248, 1971.

HINTZ, H. F. Horse Nutrition: a practical guide. New York: Arco Publishing. Inc., 1983. p. 48-50, 
HINTZ, H. F. Nutrition reports from ICEEP-5. Equine Practices, v. 21, p. 6 - 21, 1999.

HOLLAND, J. L.; KRONFELD, D. S.; SKLAN, D.; HARRIS, P. A. Behavior of horses is affected by soy lecithin and corn oil in the diet. Journal of Animal Science, v. 74, n. 7, p 1252-1255, 1996.

HOLLAND, J. L. Calculation of fecal kinetics in horses fed hay or hay and concentrate. Journal Animal Science, v. 76, n. 5, p 1937 - 1944, 1998.

HUGHES, S. J.; POTTER, G. D.; GREENE, L. W.; ODOM, T. W.; MURRAYGERZIK, M. Adaptation of Thoroughbred horses in training to a fat supplement diet. Equine Veterinary Journal. Supplement, v. 18, p. 349-352, 1995.

JANSEN, W. L. The Effect of replacing nonestructural carbohydrates with soybean oil on the digestibility of fibre in trotting horses. Equine Veterinary Journal, v. 32, n. 1, p. 27-30, 2000.

JORGENSEN, H.; JAKOBSEN, K.; EGCUM, B. O. The influence of different protein, fat and mineral levels on the digestibility of fat and fatty acids measured at the terminal ileum and in feces of growing pigs. Acta Agriculturae Scandinavica Section A, Animal Science, v. 42, p. 177 - 184, 1992.

JORGENSEN, H.; JAKOBSEN, K.; EGCUM, B. O. Determination of endogenous fat and fatty acids at the terminal ileum and in faeces in growing pigs. Acta Agriculturae Scandinavica Section A, Animal Science, v. 43, p. 101 - 106, 1993.

JORGENSEN, H.; GABERT, M.; HEDEMANN, M. S.; JENSEN, S. K. Digestion of fat does not differ in growing pigs fed diets containing fish oil, rapeseed oil or coconut oil. The Journal of Nutrition, v. 130, p. 852-857, 1999.

JULEN, T. R.; POTTER, G. D.; GREENE, L. W.; STOTT, G. G. Adaptation to a fatsupplemented diet by cutting horses. Journal of Equine Veterinary Science, v. 15, n. 10, p. 436-440, 1995.

KANE, E.; BAKER, J. P. Utilization of an corn oil supplemented diet by the horse. Procedure Equine Nutrition .Physiology.Society, v. 5,p. 41, 1977.

KANE, E.; BAKER J. P.; BULL, L. S. Utilization os a corn oil supplemented diet by a pony. Journal of Animal Science, v. 40, n. 5, p. 1379 - 1384, 1979. 
KRONFELD, D. S.; FERRANTE, P. L.; GRANDJEAN, D. Optimal nutricion for athletic performance, with emphasis on fat adaptation in dog and horses. Journal Nutrition, v. 124, n.12, p. 2745-2753, 1994.

KRONFELD, D. S.; RODIEK, A. V.; STULL, C. L. Glycemic index, glycemic load, and glycemic dietatics. Journal Equine Veterinary Science., v. 24, p. 399-404, 2004.

KURCZ, E. V.; SCHURG, W. A.; MARCELLO, J. A.; CUNEO, S. P. Dietary fat supplementation changes lipoprotein composition in horses. In: EQUINE NUTRITION PHYSIOLOGY SYMPOSIUM, 12., 1991, Calgary. Proceedings...., 1991. p. 253.

KURCZ, E. V.; SCHURG, W. A.; MARCHELLO, J. A.; CUNEO, S. P. Postprandial changes in plasma lipoprotein components in horses fed either a control or a fatadded diet. In: EQUINE NUTRITIONAL PHYSIOLOGY SYMPOSIUM, UNIVERSITY OF FLORIDA, 1993, Gainesville, FL. Proceedings .... 1993, p. 37-38.

LAWRENCE, L. M. Nutrition and fuel utilization in athletic horse. Veterinary Clinical North America: Equine Practicing., v. 6, n. 4, p. 393 - 418, 1990.

LAWRENCE, L. M. Nutrition for competition: preventing weight loss. Equine Veterinary Education, v. 7, n. 11, p .325-329, 1995.

LEWIS, L. D. Nutrição clínica eqüina: alimentação e cuidados. 2. ed. São Paulo: Roca, 2000. 710 p.

LOWRY, G. F. Special unit and medical school laboratory technicians in New Zealand. A follow-up review and survey of training and qualifications 1970-1975. New Zealand Medicine Journal, v. 12, n. 5, p. 579, 1977.

LUHMAN, C. M.; FAIDLEY, T. D.; BEITZ, D. C. Post prandial lipoprotein composition in pigs fed diets differing in type and amount of dietary fat. Journal of Nutrition, $v$. 122 , p. 120-127, 1992.

MACHADO, G. S.; FONTES, D. O. Interações entre nutrição e reprodução de varrões - Aspectos fisiológicos e zootécnicos. CONGRESSO LATINO AMERICANO DE SUINOCULTURA, 2002, Foz do Iguaçu. Anais... 2002. p. 250-261. 
MANDARINO, J. M. G. Aspectos importantes do óleo e derivados protéicos de girassol. In: REUNIÃO NACIONAL DE PESQUISA DE GIRASSOL, 11., 1995, Goiânia. Proceedings.... 1995. p. 11.

MARCHELLO, E. V.; SCHURG, W. A.; MARCHELLO, J. A.; CUNEO, S. P. Changes in lipoprotein composition in horses fed a fat-supplemented diet. Journal of Equine Veterinary Science, v. 20, p .453-458, 2000.

MARINETTI, G. V. Disorders of lipoprotein metabolism: Dislipoproteinemias. In: MARINETTI, G.V. (Ed.). Disorders of lipid metabolism. New York: Plenum Press, 1990. p. $75-168$.

MARQUEZE, A.; KESSLER, A. M.; BERNARDI, M. L. Aumento do nível de óleo em dietas isoenergéticas para cavalos submetidos a exercícios. Ciência Rural Santa Maria, v. 31, n. 3, p. 491-496, 2001.

MAZALLI, M. R. Modificação do perfil lipidico de ovos de poedeiras com a utilização de diferentes fontes de ácidos graxos. 2000. 82 f. Dissertação (Mestrado em Qualidade e Produtividade Animal) - Faculdade de Zootecnia e Engenharia de Alimentos, Universidade de São Paulo, Pirassununga, 2000.

MCCANN, J. S.; MEACHAM, T. N.; FONTENOT, J. P. Energy utilization and blood traits of ponies fed fat-supplemented diets. Journal of Animal Science, v. 65, n. 4, p.1019-1026, 1987.

MEYERS, M. C.; POTTER, G. D.; EVANS, J. W.; GREEN, L. W. ; CROUSE, S. F. Physiologic and metabolic response of exercising horses to added dietary fat. Journal of Equine Veterinary Science, v. 9, n. 4, p. 218-223, 1989.

MEYER, H. S. Alimentação de cavalos. 2. ed. São Paulo: Varela, 1995. 303 p.

MORETTO, E.; FETT, R. Tecnologia de óleos e gorduras vegetais na indústria de alimentos. São Paulo: Varela, 1998. 152 p.

MORGADO, E.; GALZERANO L. Utilização de óleos em dietas para eqüinos. Revista Electrônica de Veterinária REDVET, v. 7, n. 10, 2006. Disponível em: http://www.veterinaria.org/revistas/redvet/ >. Acesso em: ag 2007. 
MORI, A. V. Utilização de óleo de peixe e linhaça na ração como fontes de ácidos graxos poliinsaturados ômega-3 em ovos de galinha. 2001. $162 \mathrm{f}$. Tese (Doutorado em Clinica Veterinária) - Faculdade de Medicina Veterinária e Zootecnia, Universidade de São Paulo, São Paulo, 2001.

NRC. NATIONAL RESEARCH COUNCIL. Nutrient requirements of horses. 5. ed. rev. Washington, D.C : National Academy Press, 1989. 100 p.

NRC. NATIONAL RESEARCH COUNCIL. Nutrient requirements of horses. 6. ed. rev. Washington, D.C : National Academy Press, 2007. 341 p.

OLDHAM, S. L.; POTTER, G. D.; EVANS, J. W.; SMITH, S. B.; TAYLOR, T. S.; BARNES, W. S. Storage and mobilization of muscle glycogenin exercising horses fed a fat supplemented diet. Journal Equine Veterinary Science, v. 10, n. 5, p. 13, 1990.

OSAWA, C. C.; GONÇALVES, L. A. G.; RAGAZZI, S. Titulação potenciométrica aplicada na determinação de ácidos graxos livres de óleos e gorduras comestíveis. Química Nova, v. 29, n. 3, p. 593 -599, 2006.

OTT, E. A. Chairman subcommittee on horse nutrition: nutrient requirements of horses. 5 ed. Washington: National Academy Press. 1989. 53p.

OTT, R. L. An introduction to statistical methods and data analysis. 4. ed. Belmont. CA: Wadsworth. Inc, 1993.

OVERLAND, M.; MROZ, Z.; SUNDSTOL, F. Effect of lecithin on the apparent ileal and overall digestibility of crude fat and fatty acids in pigs. Journal Animal Science, v. 72, p. 2022-2028, 1994.

PACKARD, J. C. Plasma lipid and lipoprotein metabolism in the 1990s - what we know and what we need to know. In. BETTERIDGE, D. J. Current in current perspectives. London: Ed Lipids, 1999. v. 13, p. $379-390,1999$.

PAGAN, J. D.; HINTZ, H. F. Equine energetics I. Expenditure in horses during submaximal exercise. Journal Animal Science. v. 63. p. 822 - 830, 1986.

PENZ JÚNIOR, A. M.; VIOLA, E. S. Nutrição In: SOBESTIANSKY, J.; WENTZ, I.; SILVEIRA, P. R. S.; SESTI, L. A. C. Suinocultura, produção, manejo e saúde do rebanho. Brasília: Embrapa, 1998. p. 11-26. 
PIMENTA, M. E.; LIMA, J. A. F.; FIALHO, E. T.; LOGATO, P. V. R.; MURGAS, L. D. S.; BERTECHINI, A. G. Fontes e Níveis de lipídeos em rações de leitões pós desmame. Ciências Agrotécnica, v. 27, n. 5, p. 1130 - 1137, 2001.

POTTER, G. D.; WEBB, S. P.; EVANS J. W. Digestible energy requirements for work and maintenance of horses fed conventional and fat supplemented diets. Journal Equine Veterinary Scince, v. 10, n. 3, p. 214, 1990.

POTTER, G. D.; WEBB, S. P.; EVANS, J. W. A review of reseach on digestion and utilization of fed by the equine. In: Conference on Nutrition for the horse, 13, 1992. London. Proceedings.... 1992. p. 119.

RAMMERStORFER, C.; POTTER, G. D.; CUDD, T. A. Physiological responses of mature Quarter Horses to reining training when fed conventional and fat supplemented diets. Journal of Equine Veterinary Science, v. 18, n. 5, p.175-183, 1998.

RESENDE, J. R. Utilização digestiva de dietas com óleo de milho e parâmetros sangüíneos de eqüinos em atividade moderada. 2002. 29 f. Dissertação (Mestrado em Zootecnia) - Universidade Federal de Minas Gerais, 2002.

RESENDE JR., T.; RESENDE, A. S. C.; LACERDA JR., O. V.; BRETAS, M.; LANA, A.; MOURA, R. S.; RESENDE, H. C. Efeito do nível de óleo de milho adicionado à dieta de eqüinos sobre a digestibilidade dos nutrientes. Arquivo Brasileiro de Medicina Veterinária e Zootecnia, v. 56, n. 1, p. 69-73, 2004.

RICH, G. A.; FONETNOT J. P.; MEACHAM; T. N. Digestibility of animal, vegetable and blended fats by equines. In. EQUINE NUTRITION PHYSIOLOGY SYMPOSIUM, 7., 1981 Missouri. Proccedings.... 1981. p. 30-36.

$\mathrm{RICH}, \mathrm{G}$. High fat diet effect on physical performance. Equine Science Update, v. 9, n. 5, p. 287, 1988.

SALMAN, H. P.; KIENZEK, E. ; FUHRMANN, H. Metabolic consequences of feeding ponies with marginal amounts of fat. In: EQUINE NUTRITION \& PHYSIOLOGY SOCIETY SYMPOSIUM. 11., 1991., Gainesville. Proceedings...., 1991. p. 81-82.

SCOTT, B. D.; POTTER, G. D.; GREENE, L. W.; VOGELSANG, M. M.; ANDERSON, J. G. Efficacy of a fat-supplemented diet to reduce thermal stress in exercising thoroughbred horses. In: EQUINE NUTRITION PHYSIOLOGY SYMPOSIUM, 13., 1993, California. Proceedings....,, 1993. p. 66. 
SCOTT, M. G. Dietary Fat. Washintong DC.: [Present knowledge in Nutrition], 1996. p. 44-57.

SICILIANO, P. D.; WOOD, C. H. The effect of added dietary soybean oil on vitamin E status of the horse. In: EQUINE NUTRITION PHYSIOLOGY SYMPOSIUM, 1993, University of Florida, Bainesville. Proceedings ...., 1993. p. 3 -4.

SILVA, D. J.; QUEIROZ, A. C. Análise de alimentos: métodos químicos e biológicos. 2. ed. Viçosa: Imprensa Universitária UFV, 1998, 235 p.

SNYDER, J. L.; MEACHUM, T. N.; FONTENOT, J. P.; WEBB, K. E. Heat production inpony geldings fed fat-supplemented diets. In. EQUINE NUTRITION PHYSIOLOGY SOCIETY. 7., Proceedings....,, 1981. p.144 - 145.

SPINOSA, H. S. Medicamentos que interferem nas funções gastrointestinais. In: Farmacologia Aplicada a Medicina Veterinária, 2. ed. Rio de Janeiro: Editora Guanabara koogan, 1999, p. 355.

STATISTICAL ANALISYS SYSTEM. SAS/STAT User's guide. Versão 8. Cary: SAS, 2001.

TODD, L. K.; SAUER, W. C.; CHRISTOPHERSON, R. J.; COLEMAN, R. J.; CAINE, $W$. R. The effect of level of feed intake on nutrient and energy digestibilities and rate of feed passage in horses. Journal Animal Physiology Animal Nutrition, v. 73, p.140-148, 1995.

TURATTI, J.; GOMES, R. A. R.; ATHIE, I. Lipideos: Aspectos funcionais e novas tendências. Campinas: ITAL, 2002. 78 p.

VALENTINE, B. A.; AN SAUN, R. J.; THOMPSON, K. N.; HINTZ, H. F. Role of dietary carbohydrate and fat in horses with equine polysaccharide storage myopathy. Veterinary Medical Today: Timely Topics in nutrition, v. 219, n. 11, p.1537 2002, 2001.

YAMAMOTO, M.; TANAKA, Y.; SUGANO, M. Lipid composition and cholesterol esterification in serum lipoprotein fraction of the horse, Equus Caballus.

Comparative biochemistry and physiology. B, Comparative biochemistry, v. 63, n. 3, p. 441-449, 1979. 
WATSON, T. D. G.; PACKARD, C. J.; SHEPERD, J. Plasma lipid transport in the horse (Equus caballus). Comparative biochemistry and physiology. B,

Comparative biochemistry, v. 106, n. 1, p. 27-34, 1993.

WEBB, S. P.; POTTER, G. D.; EVANS, J. W. Physioogy and metabolic response of race and cutting horses to added dietary fat. In EQUINE NUTRITION PHYSIOLOGY SYMPOSIUM, 10. 1987, Fort Collins. Proceedings....., 1987, p. 115. 